\title{
Review
}

\section{A perspective of solutions for membrane instabilities in olefin/paraffin separations: A review}

Antoniel Carlos Carolino Campos, Rodrigo Azevedo dos Reis, Alfredo Ortiz, Daniel Gorri, and Inmaculada Ortiz

Ind. Eng. Chem. Res., Just Accepted Manuscript • DOI: 10.1021/acs.iecr.8b02013 • Publication Date (Web): 09 Jul 2018

Downloaded from http://pubs.acs.org on July 16, 2018

\section{Just Accepted}

"Just Accepted" manuscripts have been peer-reviewed and accepted for publication. They are posted online prior to technical editing, formatting for publication and author proofing. The American Chemical Society provides "Just Accepted" as a service to the research community to expedite the dissemination of scientific material as soon as possible after acceptance. "Just Accepted" manuscripts appear in full in PDF format accompanied by an HTML abstract. "Just Accepted" manuscripts have been fully peer reviewed, but should not be considered the official version of record. They are citable by the Digital Object Identifier (DOI®). "Just Accepted" is an optional service offered to authors. Therefore, the "Just Accepted" Web site may not include all articles that will be published in the journal. After a manuscript is technically edited and formatted, it will be removed from the "Just Accepted" Web site and published as an ASAP article. Note that technical editing may introduce minor changes to the manuscript text and/or graphics which could affect content, and all legal disclaimers and ethical guidelines that apply to the journal pertain. ACS cannot be held responsible for errors or consequences arising from the use of information contained in these "Just Accepted" manuscripts. 


\title{
A perspective of solutions for membrane instabilities in olefin/paraffin separations: A review
}

\author{
Antoniel Carlos C. Campos ${ }^{a, b}$, Rodrigo A. dos Reis ${ }^{b}$, Alfredo Ortiz $^{a}$, Daniel Gorri ${ }^{a}$, Inmaculada \\ $\operatorname{Ortiz}^{a^{*}}$ \\ ${ }^{a}$ Department of Chemical \& Biomolecular Engineering, University of Cantabria, Av. Los Castros \\ s/n., 39005 Santander, Spain. \\ ${ }^{\mathrm{b}}$ Institute of Chemistry, Rio de Janeiro State University (UERJ), Campus Maracanã, P H L C, \\ São Francisco Xavier St., 524, Rio de Janeiro, RJ, Brazil, 20550-900. \\ *e-mail: ortizi@unican.es
}

Submitted to Industrial and Engineering Chemistry Research

Revised manuscript - July 2018 


\begin{abstract}
:
Light olefins are mainly produced by the naphtha steam cracking, which is among the more energy intensive processes in the petrochemical industry. To save energy, some alternatives have been proposed to partially replace or combine with cryogenic distillation, the conventional technology to separate olefins and paraffins. Within this aim, facilitated transport membranes, mainly with $\mathrm{Ag}^{+}$cations as selective carriers, have received great attention owing to the high selectivity and permeance provided. However, to be used industrially, the undesirable instability associated to the $\mathrm{Ag}^{+}$cation should be considered. Poisonous agents and polymer membrane materials are sources of $\mathrm{Ag}^{+}$deactivation. In recent years, great achievements on the separation performance have been reported, but the current challenge is to maintain the selectivity in longterm separation processes. This work presents a critical analysis of the potential causes of $\mathrm{Ag}^{+}$ deactivation and points out some alternatives that have been proposed to overcome the hurdle. This review highlights and critically analyses some perspectives of the ongoing development and application of facilitated transport membranes.
\end{abstract}

KEYWORDS: Olefin/paraffin separations; Facilitated transport membranes; Silver salts; Silver nanoparticles; Carrier poisoning. 


\section{INTRODUCTION}

Light olefins are the principal raw material to the petrochemical industry. ${ }^{1}$ In 2016, the global ethylene and propylene production was 146 and 99 million tons and the expected of demand growth rate, until 2025 , is $3.6 \% /$ year and $4.0 \% /$ year, respectively. ${ }^{2}$ Steam cracking (SC) is the main industrial process to manufacture light olefins from naphtha or light alkanes. ${ }^{2-5}$ In petrochemical industry, SC is among the more energy-intensive processes, and, in 2016, the worldwide consumption have been estimated to be about $3.0 \cdot 10^{15}$ BTU. $^{6,7}$ After pyrolysis, separation section is the second large energy consumption step in SC (about $7.5 \cdot 10^{14} \mathrm{BTU}$ ). ${ }^{2,5-7}$ The justification for this consumption is based on the cryogenic distillation of the cracked gases. $^{6,8,9}$

Membrane processes have been proposed to save energy in the separation section by replacing or integrating with the current cryogenic distillation technology. ${ }^{10-17}$ Membrane technology has achieved very promising results, specifically regarding the olefin/paraffin separations. ${ }^{18-24}$ In a recent study, Lee et al. ${ }^{25}$ identified the optimum membrane performance required to replace one typical C3 splitter. They found that a set of membrane modules with propylene permeance of 11.3 GPU ( $\left.1 \mathrm{GPU}=1 \times 10^{-6} \mathrm{~cm}^{3}(\mathrm{STP}) / \mathrm{cm}^{2} \mathrm{~s} \mathrm{cmHg}\right)$ and selectivity of 68 could substitute a typical distillation process. Since the replacement of the distillation column by membrane units with optimum performance is technically viable, the great challenge for membrane technology is to reach the suitable selectivity and permeability for the process and keep them over long-term operation. The operational conditions in which the membrane should be used are severe and can lead to the performance loss along the operation..$^{23,24,26-28}$

Besides the steam cracking (SC) plants, which constitute the main target application, there are other two potential areas where membrane technology could be applied for olefin/paraffin 
separations. Olefin/paraffin separation membranes could be used in the recovery of propylene from FCC off-gas streams ${ }^{29-32}$ and in vent streams of some kinds of petrochemical reactors, e.g., polypropylene reactors. ${ }^{33}$ The recovery of olefins from vent streams is very attractive because milder operational conditions are present (low level of sulfur and acetylene compounds) and the performance required is lower (selectivities of 3-5) than needed in SC process and FCC off-gas streams. ${ }^{33}$ Maybe, this market niche can represent a previous favorable step before the attempt to replace distillation in the SC process or in the FCC off-gas streams that involves huge challenges to be overcome. ${ }^{31,33}$

Among membrane technologies, the alternatives based only on the solution-diffusion mechanism are not effective enough to discriminate olefin/paraffin pairs. The similarity between the physico-chemical properties of alkenes and alkanes is the main drawback that all dense-type membranes assigned to the separation face. ${ }^{34}$ The carbon molecular sieve membranes suffer of the same problem, since there is a tiny difference between the molecular diameter of the molecules to be separated. ${ }^{15}$ Nevertheless, many efforts have been focused to improve the separation using mixed matrix membranes by introduction of zeolites, ${ }^{35,36}$ organic and metal-organic frameworks ${ }^{37-41}$ in the polymer matrix. Other works focused on carbon molecular sieve membranes ${ }^{10,42,43}$ that are brittle and difficult to scale-up the production. ${ }^{25}$ To overcome these discriminative issues between the molecules, the facilitated transport of olefins has been explored, increasing simultaneously the permeance and the selectivity of the separation. The facilitated transport can be defined as a process in which chemically distinct carrier species form complexes with a specific component in the feed stream, thereby increasing the flux of this component relative to other components. ${ }^{44}$ The facilitated transport membranes have surpassed 
the upper bound of the Robeson diagram for the olefin/paraffin separation in the last few years, ${ }^{22,45}$ demonstrating the greater potential of this technological option.

Considering the potential applicability of the membrane technology for light olefins/paraffins separation, the goal of this work is to critically review the development of facilitated transport membrane for this separation highlighting the challenges and main drawbacks surpassed during the last decades. A comprehensive analysis of the instability/deactivation problems confronted by distinct kinds of membranes is carried out. The alkene/alkane membrane separation technology is presented describing the source of poisonous agents for the principal carrier used, i.e. the $\mathrm{Ag}^{+}$. Finally, some recent strategies are pointed out as options that try to overcome the $\mathrm{Ag}^{+}$deactivation by smart solutions.

\section{FACILITATED TRANSPORT MEMBRANES FOR OLEFIN/PARAFFIN SEPARATION}

The development of new membranes based on polymeric materials or the modification of polymer structures that provide suitable selectivities for the olefin/paraffin separation has been largely investigated. ${ }^{46-48}$ As the polymer films have become more selective to the olefins, they lose productivity due to the trade-off between selectivity and permeation flux, therefore, leading to the technical unfeasibility of the separation process. ${ }^{15,49}$ Films where mass transport is based only on the solution-diffusion mechanism have shown, as best results, ideal selectivity of 27 $\left(\mathrm{C}_{3} \mathrm{H}_{6} / \mathrm{C}_{3} \mathrm{H}_{8}\right)$ and 0.8 Barrer of propylene permeability. ${ }^{48,49}$ These values are significantly lower than the performance reported for facilitated transport films that have shown mixture selectivities $\left(\mathrm{C}_{2} \mathrm{H}_{4} / \mathrm{C}_{2} \mathrm{H}_{6}\right)$ higher than $100{ }^{45}$ 
The facilitated transport mechanism, when it takes place, plays in a complementary mechanism to the solution-diffusion transport. In the facilitated transport, a carrier agent interacts reversibly and selectively with the target molecule, that results in the increase in the driving force for the permeation flux of target molecule, and therefore, the permeate is enriched. This kind of transport is not accessible to the inert molecules that are not able to interact with the carrier agent, so that their concentration decreases in the permeate side (Figure 1). Thus, the facilitated transport membrane has a superior selectivity compared to the passive (solution-diffusion) membrane..$^{27,45,50,51}$ The carriers need to be effectively dispersed over the natural diffusional path of the gases (in the direction of the concentration gradient) and be present at a concentration high enough for transport activation. Furthermore, the carriers also need to be ready to the interaction with the target molecules inside the membrane, i.e., the carriers should be not poisoned. ${ }^{52,53}$

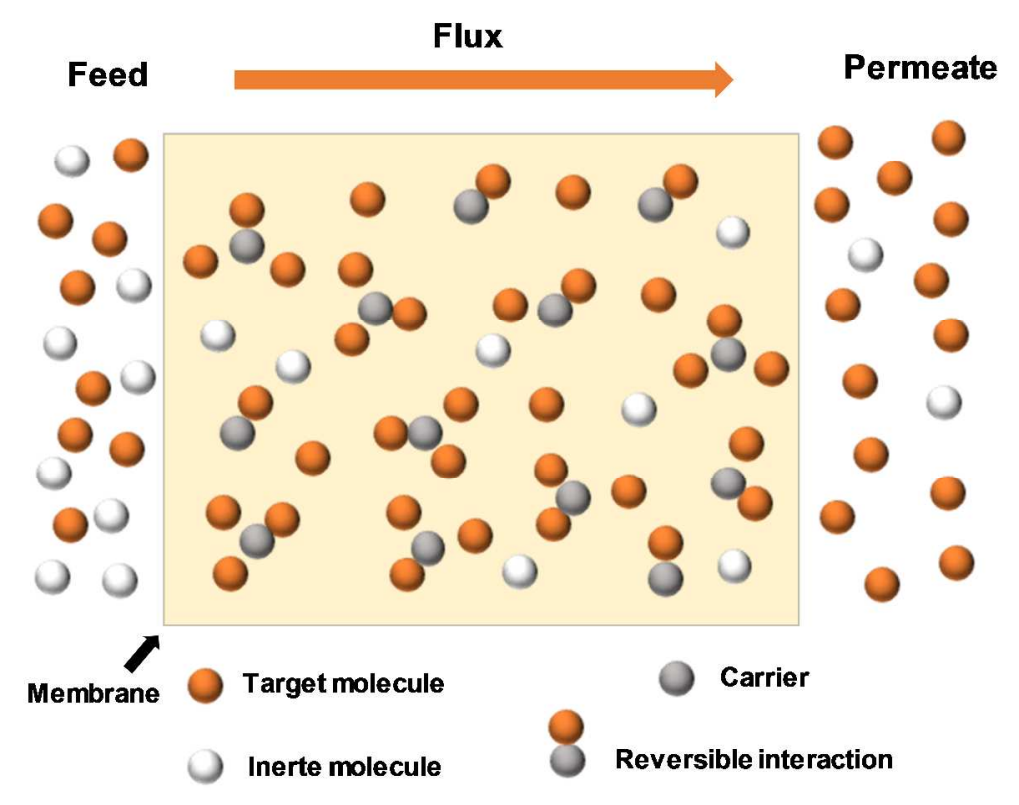

Figure 1. Representation of the facilitated transport mechanism through selective membranes. 


\subsection{Chemical interaction for olefin separation: Olefin $\pi$ complexation.}

The formation of complexes between some metals and the double bond of olefins has been well known since longtime. Nevertheless, only in 1827, the first metal-olefin complex was identified. The referred compound was the platinum (II) -ethene, which was known as Zeise complex. In the beginning of the $20^{\text {th }}$ century, the first ideas of using silver (I) $\left(\mathrm{Ag}^{+}\right)$salts in olefin absorption systems arose. However, only in 1951, Dewar $^{54}$ gave a satisfactory explanation to the interaction mechanism between the ethene and $\mathrm{Ag}^{+}$. Shortly after, Chatt and Duncanson ${ }^{55}$ advanced the Dewar's explanation presenting the interaction mechanism called $\pi$-bond complexation. ${ }^{13}$ This complexation takes place when the bonding orbital of the olefin donates electronic density to the empty outermost orbital of $\mathrm{Ag}^{+}(5 \mathrm{~s})$ making a $\sigma$ bond. The strength of this bond depends on the magnitude of the metal positive charge (e.g. silver, copper, and gold). The second bond formed is a $\pi$ bond, resulting from the backdonation of the electronic density from the outermost atomic orbital $4 \mathrm{~d}$, which is electronically completed, to the $\pi^{*}$ - antibonding molecular orbital of the olefin (Figure 2)..$^{56,57}$

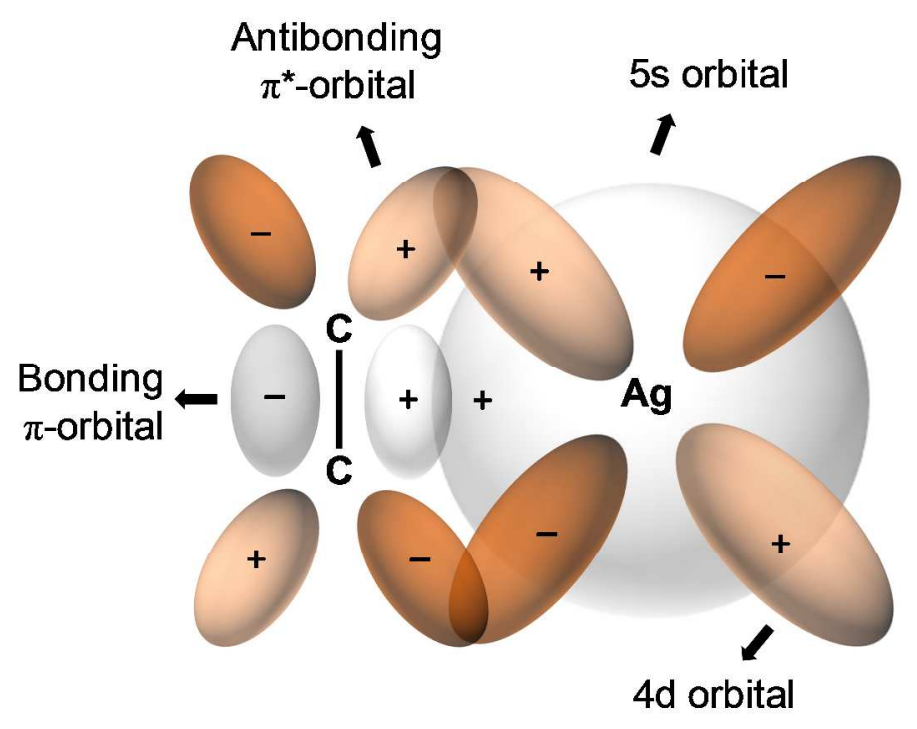


Figure 2. $\pi$ complexation between olefin and $\mathrm{Ag}^{+}$ions (Adapted with permission from Eldridge. ${ }^{58}$ Copyright 1993 American Chemical Society).

In 1960, Scholander ${ }^{59}$ published a pioneering work that explored the facilitated transport in liquid membranes containing hemoglobin as carrier agent for oxygen transport. Thereafter, works that described membranes of facilitated transport have grown for several applications. ${ }^{60}$ Over the following decades to the present day, the facilitated transport mechanism has attracted great attention of many researchers due to the separation potential compared to the simple mechanism of passive transport.

Practically, the development of facilitated transport membranes for light olefin/paraffin separations has been based on the feature of the reversible interaction among olefins and some transition metals, especially silver, copper and gold. Additionally, the $\pi$ complexation should be strong enough to favor the interaction between the metal and at the same time allow the complexation reversibility under the appropriate operational conditions. Among transition metals, silver has one singularity related to $\pi$ complexation. The silver electronegativity is 2.2 , in the range $1.6-2.3$ in which the reversible complexation can take place. ${ }^{61}$ In addition, the silver salts that have been applied in facilitated transport of olefins have the lowest lattice energies compared to other metallic salts that can be also used for this goal. A salt with low lattice energy favors the solubility of the metal cation and hence it also favors its availability for the interaction with the olefin. ${ }^{27,62}$ Owing to these features, silver is the metal most widely used in the preparation of facilitated transport membranes for olefin/paraffin separation. Nevertheless, the use of copper is the second option due to the lower price of this metal ${ }^{25}$. The price is a critical issue when the final goal is to scale up the production of this kind of membrane and therefore it 
should be considered. However, up to now, the use of the $\mathrm{Cu}^{+}$cation has not proved to be a feasible option for the facilitated transport of olefins due to the stability issues of this cation against oxidizing agents, ${ }^{63}$ although some promising studies have recently been published about the use of ionic liquids as solvents that stabilize cuprous ions. ${ }^{64}$

Based mainly on the use of silver salts, the principal carrier, facilitated transport membranes for olefin/paraffin separations started to be developed initially as supported liquid membranes. After, in the search for superior mechanical stability, ion exchange and electrolyte membranes were applied to the olefin/paraffin separations.

\subsection{Facilitated transport membranes.}

\subsubsection{Supported liquid membranes.}

In 1973, Steigelmann and Hughes ${ }^{65}$, working in the Standard Oil Company, started to develop films of cellulose acetate with silver nitrate solution in the pores of the membrane (support) (Figure 3). The solution is held in the pores of the support by capillary forces. The best initial result achieved for mixture selectivity $\left(\mathrm{C}_{2} \mathrm{H}_{4} / \mathrm{C}_{2} \mathrm{H}_{6}\right)$ was $c a 1280$ and a mixture permeance of 30 GPU. Motivated by the preliminary results, they have developed these films for more than 10 years. ${ }^{66}$ However, spite of all efforts, they have not had success in the commercialization of this technology. The main problem found by them was the poor stability of the $\mathrm{Ag}^{+}$solution in the membrane pores. During the separation process, the solution was gradually swept out from the pores due to the dragging effect of the gas stream, dropping the selectivity of the process. To solve this problem, some subsequent works ${ }^{27,67-70}$ have focused on improving the stability of the solutions inside the pores of the membranes. However, the inherent instability of the supported 
liquid membranes continues to be a limiting feature in the commercial application of this membrane configuration.

Common performances of supported liquid membranes show selectivity values $(\alpha)$ ranging from 100 ( $\alpha$ of $\mathrm{C}_{3} \mathrm{H}_{6} / \mathrm{C}_{3} \mathrm{H}_{8}$ using triethylene glycol/ $/ \mathrm{AgBF}_{4} 43$ wt.\% with humidified feed stream $)^{67}$ to 1000 ( $\alpha$ of $\mathrm{C}_{2} \mathrm{H}_{4} / \mathrm{C}_{2} \mathrm{H}_{6}$ using $\mathrm{AgNO}_{3} 4 \mathrm{M}$ with humidified feed stream $)^{71}$ and permeances from 4 to $27 \mathrm{GPU}$ of olefin, respectively. High permeances are achieved due to low mass transport resistance through liquid medium. The use of humidified feed stream is required to avoid the drying of solution held in support pores. The support can be prepared of microporous membranes made of cellulose, polyvinilydene diflouride (PVDF), and polytetrafluoroethylene (PTFE) ${ }^{67,71-73}$ Indeed, the disadvantage for this membrane configuration are the real risks of dragging out the carrier solution from support pores.

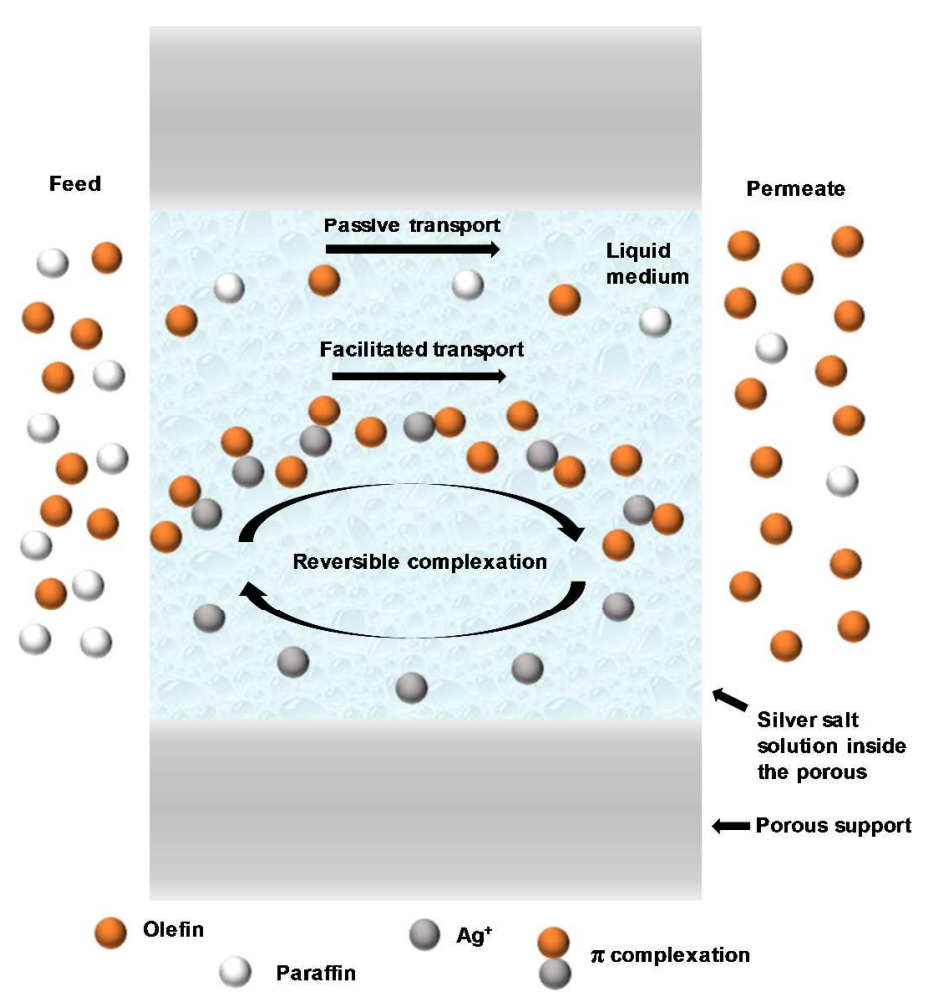

Figure 3. Supported liquid membrane. 


\subsubsection{Ion exchange membranes.}

In the 1980 's, to solve the problems with the supported liquid membranes resulting from the $\mathrm{Ag}^{+}$solution sweeping out by the passage of the gas stream, LeBlanc and co-workes ${ }^{74}$ proposed the use of ion-exchange membranes. From this work, several other groups started to research this kind of strategy. ${ }^{18,75-81}$ The ion-exchange membranes are generally prepared by the addition of the silver salt to the membrane, which is formed by a polymer functionalized with an acid group, (e.g. sulfonic acid group) able to exchange $\mathrm{H}^{+}$for the $\mathrm{Ag}^{+}$. To achieve the ion-exchange, the polymer should be immersed in the $\mathrm{Ag}^{+}$solution or other metallic salt solution. Next, the membrane should be humidified. Without water, the $\mathrm{Ag}^{+}$ions are so strongly attached to the anionic sites in the membrane that makes very difficult the interaction with the olefin (Figure 4). Working with humidified feed streams, several interesting works have been reported in literature. For instance, Eriksen et al. ${ }^{75}$ applied Nafion (N-117), which was preswollen in glycerine and soaked in aqueous $\mathrm{AgBF}_{4} 6 \mathrm{M}$, for separation of $\mathrm{C}_{2} \mathrm{H}_{4} / \mathrm{C}_{2} \mathrm{H}_{6}(1: 1$ molar ratio) humidified stream. The membrane provided a selectivity of 1930 and $\mathrm{C}_{2} \mathrm{H}_{4}$ permeability of 26800 Barrer or about 83 GPU.

As the carrier agent cannot be easily swept out from the membrane by the gas streams, the ionexchange membranes have a vast advantage compared to supported liquid membranes. Despite their advantages, ion-exchange membranes formed by an ion-exchange polymer are usually more expensive and the required humidification is not desirable because it requires an additional operation step aimed at drying the outlet gas streams from the membrane unit. ${ }^{27,28}$ For this kind of membrane configuration, olefin/paraffin selectivity values between 290 and 1900, and olefin permeances ranging from 5 GPU to 83 GPU have been reported (always with humidified feed 
streams). The main polymeric materials used as matrix for ion-exchange membranes are Nafion and sulfonated polyphenyleneoxide. ${ }^{74,75}$

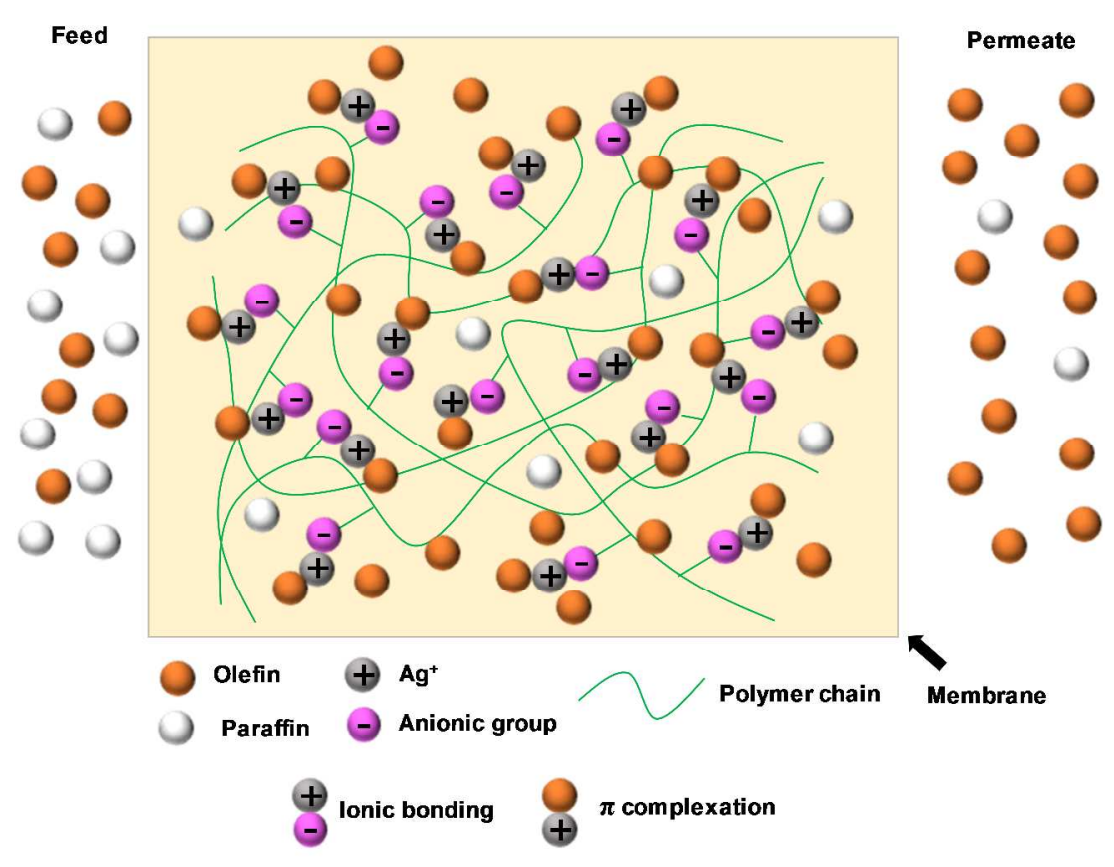

Figure 4. Ion-exchange membranes.

\subsubsection{Electrolyte membranes.}

During the 1990 's and 2000 's, to overcome the problems originated from the humidification dependence of the ion-exchange membranes, the development of dense materials denominated as polymer electrolyte membranes took place. ${ }^{20,82-84}$ Among others, the research groups of Ingo Pinnau ${ }^{83,85-87}$ and Yong Soo Kang ${ }^{84,88-91}$ stood out during the last few years. Pinnau and Toy ${ }^{83}$ reported that it was possible to dissolve silver salts in a hydrophilic polymer with polar functional groups able to coordinate with $\mathrm{Ag}^{+}$ion, e.g. polyether. In this kind of membrane, the facilitated transport was developed without humidification of the flowing gas, which represented 
a great achievement compared to the ion-exchange membranes. Kang et al. ${ }^{45,51,62,84,92,93}$ followed this method and dissolved silver salts in others polar polymer matrices as poly(2-ethyl-2oxazoline) (POZ), polyvinylpyrrolidone (PVP) and poly(styrene-b-butadiene-b-styrene) (SBS). The results obtained with polymer electrolyte materials have by far exceeded the previous results of supported liquid and ion-exchange membranes. In 2006, the Kang`s group, ${ }^{45}$ using the polymer electrolyte membranes with different silver salts and polymers, was able to surpass the upper bound of Robeson diagram with selectivities and permeabilities never achieved before. For instance, the ideal separation factor (pure gas permeation) of propylene/propane was above 10,000 with 45 GPU of propylene permeance. ${ }^{62}$ In the permeation of gas mixtures, the selectivity dropped to 40-60 due to the plasticization effect that occurred in the membranes. ${ }^{51}$

Inside the polymer matrix, the $\mathrm{Ag}^{+}$cations can be arranged as free ions, ion pairs or higher order aggregates. ${ }^{94}$ In this context, the term "free ions" should be understood as the $\mathrm{Ag}^{+} \mathrm{cations}^{\circ}$ dissolved in the polymer matrix. The best way for the salt to be in the membrane is in the form of free ion, because the silver is more available to the interaction with the olefin. ${ }^{90,94-96}$ To reach the desired amount of free ions in the electrolyte membrane, normally, the polymer should have suitable functional groups (e.g. ether, amide, lactam, ester, alcohol and aromatic or aliphatic double bond) to interact with the $\mathrm{Ag}^{+}$cations (Figure 5a). Polymers like poly(2-ethyl-2oxazoline) (POZ), poly(ethylene oxide) (PEO), polyvinylpyrrolidone (PVP), polymethacrylates (PMA), poly(vinyl alcohol) (PVA), poly(styrene-b-butadiene-b-styrene) (SBS), poly(ethylene phthalate) (PEP), ${ }^{45,51,62,84,92,93}$ poliurethanes (PU) based on polyether or polyester ${ }^{21,97-99}$ and poly(ether-block-amide) (best known under the trademark Pebax $\left.{ }^{\circledR}\right)^{28,100,101}$ are used as suitable polymer matrix to maintain the dissolution of the silver salts in solid electrolyte membranes. The lower lattice energy of the salt is also crucial in this point to provide an easier way to dissolve the 
compound. Regarding this aspect, $\mathrm{AgBF}_{4}$ is the most widely used salt due to its lowest lattice energy among ordinary silver salts for this purpose. ${ }^{27,62}$ At this point, in an attempt to increase the degree of salt dissociation inside the polymer electrolytes, a couple of investigations have proposed the addition of asparagine ${ }^{102}$ in the $\mathrm{POZ} / \mathrm{AgBF}_{4}$ membranes and the use of a mixture of silver salts ${ }^{103,104}$ to improve the salt dissociation inside the polymer matrix.

Nevertheless, the interaction among the polymer functional group and the $\mathrm{Ag}^{+}$salt may cause the reduction of $\mathrm{Ag}^{+}$cation to $\mathrm{Ag}^{0}$ metallic. Over the time, the $\mathrm{Ag}^{0}$ growth and agglomeration cause the formation of some defects or holes at the interface between the metal particle and the polymer chains. Without discrimination, the gases can easily pass through this path with lower mass transport resistance that leads to selectivity loss in long-term permeation experiments. ${ }^{26}$ Trying to solve this problem, several works have investigated solutions to overcome this drawback. In 2001, Jose et al. ${ }^{105}$ retarded the formation of $\mathrm{Ag}^{0}$ by incorporating phthalates to the membranes of $\mathrm{PVP} / \mathrm{AgBF}_{4}$ (Table 1). The stabilization of $\mathrm{Ag}^{+}$cation is due to the strong interaction between the carbonyl groups of phthalates and the $\mathrm{Ag}^{+}$that plays a key factor in slowing down the reduction induced by the lactam group of PVP. This was the pioneer work that started to report long-term experiments regarding the stability of polymer membranes containing silver salts. In attempt to avoid the $\mathrm{Ag}^{0}$ growth and agglomeration, Park et al. ${ }^{106}$ added a nonionic surfactant (n-octyl $\beta$-D-glucopyranoside (8G1)) to the same kind of membrane to provide a steric hindrance effect hampering the metal particles coalescence. The protective layer onto the surface of formed silver particles was responsible to maintain the stability of membrane performance for 30 days (Table 1). However, the reduction problems were not solved by this strategy. 
The reduction of $\mathrm{Ag}^{+}$by polymers like $\mathrm{POZ}$ normally results in an increase of $\mathrm{H}^{+}$ion concentration in the medium. ${ }^{107}$ This is possible because the membrane contained a small amount of water favored by the hygroscopicity of salts like $\mathrm{AgBF}_{4}{ }^{108}$ To suppress the $\mathrm{Ag}^{+}$ reduction process, Kim et al ${ }^{89}$ proposed the introduction of $\mathrm{HBF}_{4}$ in $\mathrm{POZ} / \mathrm{AgBF}_{4}$ membranes. The goal was to shift the equilibrium of the reduction reaction toward the regeneration of $\mathrm{Ag}^{+}$, preventing the formation of metallic silver. To investigate this proposal, they performed permeation tests under UV irradiation. As a result, it was found that tiny amounts of $\mathrm{HBF}_{4}$ could indeed suppress the reduction of $\mathrm{Ag}^{+}$. $\mathrm{A} \mathrm{POZ} / \mathrm{AgBF}_{4}$ membrane with the molar ratio of 1[carbonyl oxygen]:1[ $\left.\mathrm{Ag}^{+}\right]$exhibited a selectivity of about 100 (50:50 vol.\% of $\mathrm{C}_{2} \mathrm{H}_{4} / \mathrm{C}_{2} \mathrm{H}_{6}$ ) but, after $4 \mathrm{~h}$ under $\mathrm{UV}$ irradiation, the selectivity dropped to 1 . When $\mathrm{HBF}_{4}$ was introduced in the membrane with the molar ration of $1\left[\right.$ carbonyl oxygen]:1[ $\left.\mathrm{Ag}^{+}\right]: 0.2\left[\mathrm{HBF}_{4}\right]$, the selectivity was maintained in the same initial value after $4 \mathrm{~h}$ under UV irradiation, thus having suppressed the $\mathrm{Ag}^{+}$reduction process inside the material. Although this procedure has been effective in laboratory studies, it seems an alternative difficult to implement on a large scale.

On the other hand, Kang et al. ${ }^{109}$ interestingly suggested the introduction of $\mathrm{Al}\left(\mathrm{NO}_{3}\right)_{3}$ in $\mathrm{POZ} / \mathrm{AgBF}_{4}$ membranes (Table 1) to suppress $\mathrm{Ag}^{+}$ion reduction. The function of $\mathrm{Al}\left(\mathrm{NO}_{3}\right)_{3}$ is to weaken the interaction between the functional group of the polymer and the $\mathrm{Ag}^{+}$due to the favorable electrostatic interaction between $\mathrm{Ag}^{+}$and $\mathrm{NO}_{3}{ }^{-110,111}$ The mutual interaction between the ions, i.e. $\mathrm{Ag}^{+} / \mathrm{NO}_{3}{ }^{-}$and $\mathrm{Al}^{3+} / \mathrm{BF}_{4}^{-}$, is responsible for changing the chemical environment of the $\mathrm{Ag}^{+}$. Compared to the neat $\mathrm{POZ} / \mathrm{AgBF}_{4}$, the presence of $\mathrm{Al}\left(\mathrm{NO}_{3}\right)_{3}$ decreases the binding energy of the valence electron in the silver atom, which is verified by X-ray photoelectron spectroscopy (XPS) analysis. By modifying the electronic density of the silver atom, it is possible to adjust the intensity of the interaction between the $\mathrm{Ag}^{+}$and polymer functional group, 
reducing the oxidative power of the $\mathrm{Ag}^{+}$(Figure 5b). Using this strategy, it was possible to maintain the selectivity of the membrane for 14 days in long-term permeation tests. ${ }^{109}$

a)

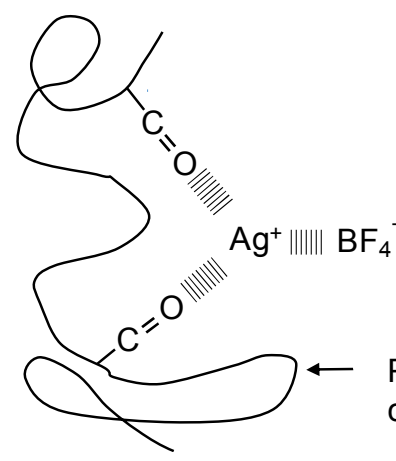

b)

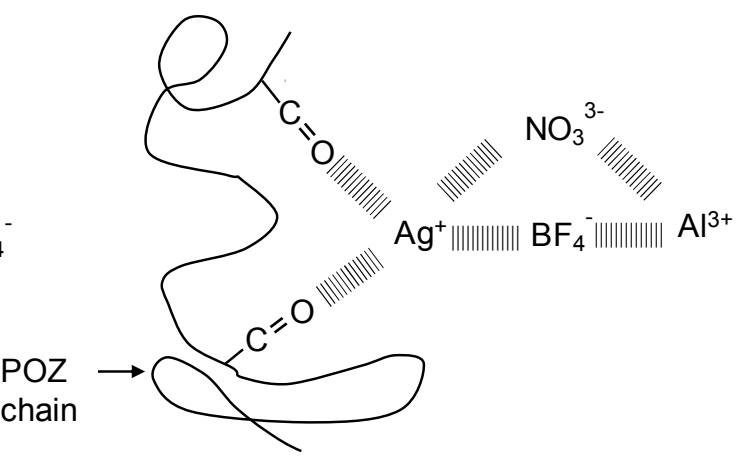

Figure 5. a) Interaction between the functional groups of $\mathrm{POZ}$ (amide $\mathrm{C}=\mathrm{O}$ ) with the $\mathrm{Ag}^{+}$from $\mathrm{AgBF}_{4}$ and b) the mutual interaction between the $\mathrm{Ag}^{+} / \mathrm{NO}_{3}{ }^{-}$and $\mathrm{Al}^{3+} / \mathrm{BF}_{4}{ }^{-}$that weakens the former interaction between the $\mathrm{C}=\mathrm{O}$ group of polymer.

Also in an attempt to solve the problems related to the essential instability of $\mathrm{Ag}^{+}$inside polar polymer matrices, Kang et al. ${ }^{90}$ showed a way to disperse silver salts in polydimethylsiloxane (PDMS), which is an inert polymer matrix, and yet reach the facilitated transport (Table 1). The $\mathrm{Ag}^{+}$does not share the same interaction observed in polar matrixes, leading to the formation of silver salt aggregates trapped in the polymer domains. At first glance, it seemed that it would not work, since the preferable interaction with the olefin takes place with silver free ions. However, in permeation tests, when the olefinic gases began to pass through the membrane, the olefin complexation gradually dissolved the silver salt aggregates into free ions, promoting the facilitated transport. The time to reach the dissolution was about $100 \mathrm{~h}$, after that, steady-state transport was achieved. Following this approach, it was possible to reach mixed gas selectivity of 
about 200, propylene permeance of about 15 GPU and keep the values constant for one week. This remarkable result brought the knowledge that introduction of silver salt in inert polymers, i.e. polymers that do not have functional groups to dissolve the silver salt, is feasible; and yet, they can promote the facilitated transport of olefins.

In the set of electrolyte membranes, the longest-term permeation test was performed in a $\mathrm{PVP} / \mathrm{AgBF}_{4} / \mathrm{n}$-octyl $\beta$-D-glucopyranoside (8G1) membrane. Along 30 days, the presence of nonionic surfactant (8G1) provided a stable membrane performance (mixture selectivity $\mathrm{C}_{3} \mathrm{H}_{6} / \mathrm{C}_{3} \mathrm{H}_{8}$ $=60$ and mixed gas permeance of $34 \mathrm{GPU}$ ) with the highest permeance reported for electrolyte membranes. ${ }^{106}$ The introduction of $8 \mathrm{G} 1$ only avoided the $\mathrm{Ag}^{0}$ growth and agglomeration, however the reduction problems remained unsolved. Among attempts that indeed try to protect $\mathrm{Ag}^{+}$cation against reduction, $\mathrm{POZ} / \mathrm{AgBF}_{4} / \mathrm{Al}\left(\mathrm{NO}_{3}\right)_{3}$ membrane showed a stable performance (mixture selectivity $\mathrm{C}_{3} \mathrm{H}_{6} / \mathrm{C}_{3} \mathrm{H}_{8}=21$ and mixed gas permeance of $4.8 \mathrm{GPU}$ ) for 14 days. ${ }^{109}$ The highest selectivity value was found in $\mathrm{PDMS} / \mathrm{AgBF}_{4}$ membrane with a stable performance (mixture selectivity $\mathrm{C}_{3} \mathrm{H}_{6} / \mathrm{C}_{3} \mathrm{H}_{8}=200$ and mixed gas permeance of 15 GPU) for 7 days. ${ }^{90}$ In general, the selectivity values can vary from 5 to 200 and the mixed gas permeance from 0.5 to 34 GPU..$^{90,106,110}$ The time reported in long-term permeation tests ranges from 4 to 30 days. $^{90,110,112}$

PVP is the most used polymer for electrolyte membranes of polar matrix; however, membranes made of PDMS, which is an inert matrix, have shown the highest selectivity values. Despite all efforts, the selectivity loss caused by $\mathrm{Ag}^{+}$cation reduction remains unsolved for permeation tests longer than 2 weeks. Considering simultaneously selectivity, permeance, and separation stability, the best result is performed by $\mathrm{PDMS} / \mathrm{AgBF}_{4}$ membrane, indicating that the use of inert matrixes is a promising strategy to develop new electrolyte membranes for olefin/paraffin separation. To 
avoid the reduction of $\mathrm{Ag}^{+}$inside the polymer matrix, besides the silicone-based polymers, other polymer class, which is well known by its intrinsic inertness, is thought to be used as membrane material. Fluoropolymers have been used in the latest works trying to solve the problem of $\mathrm{Ag}^{+}$ instability. ${ }^{22,113}$ In general, since $\mathrm{Ag}^{+}$is a stronger oxidant, the aim is that the polymer to be used as membrane does not have any group that could be oxidized by the $\mathrm{Ag}^{+}$cation.

Table 1. Results of long-term permeation tests of various electrolyte membranes.

\begin{tabular}{|c|c|c|c|c|c|c|}
\hline Polymer & $\begin{array}{l}\text { Carrier/ } \\
\text { stabilizer } \\
\text { Fraction (\%) }\end{array}$ & $\begin{array}{l}\text { Separation } \\
\text { performance } \\
\text { (days) }\end{array}$ & Selectivity $^{\mathrm{c}}$ & $\begin{array}{l}\text { Mixed gas } \\
\text { permeance } \\
\text { (GPU) }\end{array}$ & $\begin{array}{l}\text { Olefin } \\
\text { purity } \\
(\mathrm{mol} \%)\end{array}$ & Reference \\
\hline \multicolumn{7}{|c|}{ Electrolyte membranes of polar matrix } \\
\hline \multirow[t]{2}{*}{ PVP } & $\mathrm{AgBF}_{4} / \mathrm{DOP}$ & 4.2 & 160 & 7.5 & 99.4 & In 2001 \\
\hline & $50.0^{\mathrm{a} *} 2.0^{\mathrm{b*}}$ & & & & & $\begin{array}{l}\text { Jose } \\
\text { al. }^{105}\end{array}$ \\
\hline \multirow[t]{2}{*}{ PVP } & $\mathrm{AgBF}_{4} / \mathrm{DPP}$ & 4.2 & 135 & 10 & 99.3 & In 2001, \\
\hline & $50.0^{\mathrm{a}^{*} / 2.0^{\mathrm{b}^{*}}}$ & & & & & $\begin{array}{l}\text { Jose et } \\
\text { al. }^{105}\end{array}$ \\
\hline \multirow[t]{2}{*}{ PVP } & $\mathrm{AgBF}_{4} / \mathrm{DBP}$ & 4.2 & 85 & 9 & 98.8 & In 2001, \\
\hline & $50.0^{\mathrm{a}^{*} / 2.0^{\mathrm{b}^{*}}}$ & & & & & $\begin{array}{l}\text { Jose } \\
\text { al. }^{105} \quad \text { et }\end{array}$ \\
\hline \multirow[t]{2}{*}{ PVP } & $\mathrm{AgBF}_{4} / 8 \mathrm{G} 1$ & 30 & 50 & 34 & 98.0 & In 2003, \\
\hline & $49.8 / 0.5^{\mathrm{a}}$ & & & & & $\begin{array}{l}\text { Park et } \\
\text { al. }{ }^{106}\end{array}$ \\
\hline \multirow[t]{2}{*}{ PVP } & $\mathrm{AgBF}_{4} / 8 \mathrm{G} 1$ & 30 & 60 & 34 & 98.4 & In 2003, \\
\hline & $49.9 / 0.2^{\mathrm{a}}$ & & & & & $\begin{array}{l}\text { Park et } \\
\text { al. }{ }^{106}\end{array}$ \\
\hline \multirow[t]{2}{*}{ PEP } & $\mathrm{AgNO}_{3}$ & 7 & 16.2 & 5.4 & 94.2 & In 2006, \\
\hline & $50.0^{\mathrm{a}}$ & & & & & $\begin{array}{l}\text { Kang } \\
\text { al. }^{114}\end{array}$ \\
\hline
\end{tabular}

$\mathrm{a}$ - molar fraction; $\mathrm{b}$ - weight fraction; $\mathrm{a}^{*}$ - molar fraction relates only to the polymer; $\mathrm{b}^{*}$ - weight fraction relates only to the polymer; c - mixed gas (50:50 vol \% of propylene/propane mixture)

$* \mathrm{Al}(\mathrm{NO} 3) 3 \cdot 9 \mathrm{H} 2 \mathrm{O}$ 
PVP - polyvinylpyrrolidone; PEP - poly(ethylene phthalate); POZ - poly(2-ethyl-2-oxazoline); PEO poly(ethylene oxide); PVA - poly(vinyl alcohol); PDMS - polydimethylsiloxane

DOP - dioctyl phthalate; DPP - diphenyl phthalate; DPB - dibutyl phthalate; $8 \mathrm{G} 1$ - n-octyl $\beta$-D-glucopyranoside.

Table 1. Continued.

\begin{tabular}{|c|c|c|c|c|c|c|}
\hline Polymer & $\begin{array}{l}\text { Carrier/ } \\
\text { stabilizer } \\
\text { Fraction (\%) }\end{array}$ & $\begin{array}{l}\text { Separation } \\
\text { performance } \\
\text { (days) }\end{array}$ & Selectivity $^{\mathrm{c}}$ & $\begin{array}{l}\text { Mixed gas } \\
\text { permeance } \\
\text { (GPU) }\end{array}$ & $\begin{array}{l}\text { Olefin } \\
\text { purity } \\
(\mathrm{mol} \%)\end{array}$ & Reference \\
\hline
\end{tabular}

Electrolyte membranes of polar matrix

\begin{tabular}{|c|c|c|c|c|c|c|}
\hline POZ & $\mathrm{AgBF}_{4} /$ & 14 & 21 & 4.8 & 95.5 & In 2013, \\
\hline & $\mathrm{Al}\left(\mathrm{NO}_{3}\right)_{3}{ }^{*}$ & & & & & Kang et \\
\hline & $47.6 / 4.8^{a}$ & & & & & \\
\hline PEO & $\mathrm{AgBF}_{4} /$ & 10 & 10 & 20 & 90.9 & In 2015 \\
\hline & $\mathrm{Al}\left(\mathrm{NO}_{3}\right)_{3}{ }^{*}$ & & & & & Song et \\
\hline & $49.9 / 0.2^{\mathrm{a}}$ & & & & & \\
\hline PVP & $\mathrm{AgCF}_{3} \mathrm{SO}_{3} /$ & 4 & 5 & 0.5 & 83.3 & In 2015 \\
\hline & $\mathrm{Al}\left(\mathrm{NO}_{3}\right)_{3}{ }^{*}$ & & & & & Sung et \\
\hline & $49.9 / 0.2^{\mathrm{a}}$ & & & & & \\
\hline PVP & $\mathrm{AgCF}_{3} \mathrm{SO}_{3} /$ & 4 & 9 & 0.5 & 90.0 & In 2016 , \\
\hline & $\mathrm{Al}\left(\mathrm{NO}_{3}\right)_{3}{ }^{*} /$ & & & & & Park and \\
\hline & $\mathrm{BMImBF}_{4}$ & & & & & \\
\hline & $43.6 / 4.1 / 8.7^{\mathrm{a}}$ & & & & & \\
\hline PVA & $\mathrm{AgBF}_{4} /$ & 6 & 17 & 11 & 94.0 & In 2017 , \\
\hline & $\mathrm{Al}\left(\mathrm{NO}_{3}\right)_{3}{ }^{*}$ & & & & & Park et al. ${ }^{26}$ \\
\hline & $49.3 / 1.5^{\mathrm{a}}$ & & & & & \\
\hline
\end{tabular}

Electrolyte membranes of inert matrix

\begin{tabular}{|c|c|c|c|c|c|c|}
\hline PDMS & $\begin{array}{l}\mathrm{AgBF}_{4} \\
73^{\mathrm{b}}\end{array}$ & 7 & 200 & 15 & 99.5 & $\begin{array}{l}\text { In } 2004, \\
\text { Kim et al. }^{90}\end{array}$ \\
\hline
\end{tabular}

$\mathrm{a}$ - molar fraction; $\mathrm{b}$ - weight fraction; $\mathrm{a}^{*}$ - molar fraction relates only to the polymer; $\mathrm{b}^{*}$ - weight fraction relates only to the polymer; $\mathrm{c}$ - mixed gas (50:50 vol \% of propylene/propane mixture) 
*Al(NO3)3.9H2O

PVP - polyvinylpyrrolidone; PEP - poly(ethylene phthalate); POZ - poly(2-ethyl-2-oxazoline); PEO poly(ethylene oxide); PVA - poly(vinyl alcohol); PDMS - polydimethylsiloxane

DOP - dioctyl phthalate; DPP - diphenyl phthalate; DPB - dibutyl phthalate; 8G1 - n-octyl $\beta$-D-glucopyranoside.

\subsection{Challenges to avoid carrier instability.}

Taking into account the results reached at laboratory scale by using polymer membranes with silver salts ${ }^{45}$, the search for higher selectivities and permeabilities in the separation process is no more a big challenge. However, the maintenance of the membrane performance in long-term operation conditions has become a new target to be surpassed. $\mathrm{Ag}^{+}$cations incorporated in the electrolyte membranes report instability problems related to the tendency of them to react with other species, deactivating or poisoning the agent carrier in long-term operation. ${ }^{28,31}$ The photoreduction or the exposition to reductant gases, e.g. hydrogen, inactivates the $\mathrm{Ag}^{+}$cation due to its reduction to metallic silver $\left(\mathrm{Ag}^{0}\right)$. The decontrolled formation of $\mathrm{Ag}^{0}$ in the membrane can damage it with negative influence on the separation performance. The $\mathrm{Ag}^{+}$cation also can react with hydrogen sulfide $\left(\mathrm{H}_{2} \mathrm{~S}\right)$ and acetylene $\left(\mathrm{C}_{2} \mathrm{H}_{2}\right)$ forming undesired compounds, principally silver acetylide that is extremely explosive and can pose a significant risk to the process. The deactivation reaction of $\mathrm{Ag}^{+}$are summarized in Table 2. It is worth emphasizing that small amounts (about $10 \mathrm{ppm}$ ) of these contaminants in the gas stream is enough to drastically decrease the process selectivity, in less than one week, impairing the membrane use. ${ }^{28}$

\section{Table 2. Deactivation reaction of silver cation $\left(\mathrm{Ag}^{+}\right)$.}

\begin{tabular}{ll}
\hline Reaction & Description \\
\hline $\mathrm{Ag}^{+}+\mathrm{e}^{-} \stackrel{u v}{\rightarrow} \mathrm{Ag}^{0}$ & Photoreduction \\
$2 \mathrm{Ag}^{+}+\mathrm{H}_{2} \rightarrow 2 \mathrm{Ag}^{0}+2 \mathrm{H}^{+}$ & Reduction by $\mathrm{H}_{2}$
\end{tabular}




\section{$\mathrm{C}_{2} \mathrm{H}_{2}+2 \mathrm{AgX} \rightarrow \mathrm{Ag}_{2} \mathrm{C}_{2}+2 \mathrm{HX} \quad$ Formation of silver acetylide $\mathrm{H}_{2} \mathrm{~S}+2 \mathrm{AgX} \rightarrow \mathrm{Ag}_{2} \mathrm{~S}+2 \mathrm{HX} \quad$ Formation of silver sulfide}

\footnotetext{
$\mathrm{X}$ is an anionic component of silver salt
}

Normally, the olefin/paraffin stream from naphtha steam cracking, which aims to be separated by membrane technology, contains some silver poisonous agents in low concentration, in ppm range. In the naphtha cracking furnace, it is necessary to operate with about $20 \mathrm{ppm}$ of sulfur compounds in the feedstock to prevent the formation of undesired carbon monoxide. The function of sulfur is to passivate the nickel and iron catalysts sites in the cracking coil material of the furnace. The $\mathrm{H}_{2} \mathrm{~S}$ formed in the cracked gases is removed together with the $\mathrm{CO}_{2}$ in the compression section using caustic solvents in absorption towers. Usually, $\mathrm{CO}_{2}$ and $\mathrm{H}_{2} \mathrm{~S}$ concentration in the overhead stream of the absorption towers is below $0.2 \mathrm{ppm} .{ }^{6,8}$

Usually, hydrogen reduced compounds and acetylene (C2 and C3) are some byproducts of the SC. Hydrogen is removed at the lowest temperatures achieved in the chilling train, together with methane; they are overhead products of the demethanizer. ${ }^{25}$ The acetylene species, i.e. acetylene, methylacetylene (MA), and propadiene (PD), are removed by catalytic hydrogenation processes that transform them into more saturated hydrocarbons. The content of acetylenic compounds in the outlet of the hydrogenation process is $<0.5 \mathrm{ppm} .{ }^{8}$ Typically, the specification of polymer grade ethylene and propylene from the $\mathrm{SC}$ is $<1 \mathrm{ppm}$ of $\mathrm{H}_{2}$ and $<4$ ppm of acetylene species. ${ }^{116}$

This severe scenario corresponds to a typical petrochemical plant where membranes are intended to be implemented. In addition, there are other challenges not related to silver poisoning. To replace or integrate $\mathrm{C} 2$ and $\mathrm{C} 3$ splitters, the membrane should treat a feed stream under a pressure of 5-20 bar and produce a permeate stream at 1-3 bar. Governed by these conditions, plasticization effects may occur even in the most rigid polymer membranes. ${ }^{11,117}$ 
Thus, withstanding the negative influence of contaminants and avoid plasticization issues are essential challenges to be overcome by the next generation membranes.

\section{ALTERNATIVES TO OVERCOME $\mathrm{Ag}^{+}$DEACTIVATION}

In this context, some research groups have focused their efforts on proposing strategies to mitigate and/or overcome the problems imposed to the separation by the deactivation of the carrier. In the scientific literature, the most prominent efforts, proposing different solution lines to these problems, seem to not have a clear consensus on what would be the most promising strategy. The alternatives, which use dense polymeric films, are (i) the use of metallic nanoparticles as carrier, mainly silver nanoparticles, (ii) the use of ionic liquids for the stabilization of $\mathrm{Ag}^{+}$, (iii) in situ regeneration of electrolyte polymeric membrane by using oxidizing agents, and (iv) the use of highly fluorinated polymers.

\subsection{Silver nanoparticles as carrier.}

As already seen, the reduction of $\mathrm{Ag}^{+}$to $\mathrm{Ag}^{0}$ throughout the separation process causes deactivation of the carrier and consequently the loss of membrane selectivity. In 2004, Kang et al., ${ }^{52}$ when performing permeation tests on a polymeric membrane with silver salts, noticed that the selectivity was reduced from 52 to 31 in $150 \mathrm{~h}$ of experiment. In parallel, it was observed the formation of metallic silver nanoparticles (Ag NP), whose size increased from 14.75 to 27.75 $\mathrm{nm}$. It should be noted that, even at the beginning of the experiment, Ag NP were formed, pointing to the difficulty in avoiding $\mathrm{Ag}^{+}$reduction. What was remarkable in this experimental observation was that, even with Ag NP of $27.75 \mathrm{~nm}$ in the membrane, the selectivity did not fall abruptly, only $40 \%$ reduction was observed. The hypothesis proposed for the maintenance of the 
Ag carrier properties was the formation of a partial charge polarization on the Ag NP surface. The phenomena observed by these authors has initiated a new study framework involving facilitated transport nanocomposite membranes of light olefins in place of $\mathrm{Ag}^{+}$salts. The great advantage of this replacement is that the problems of reduction deactivation involving the $\mathrm{Ag}^{+}$ ion would be bypassed. This would allow the maintenance of the separation properties of the membranes in long-term operation. ${ }^{118}$

In 2007, Kang et al. ${ }^{53}$ presented the first paper introducing the idea of Ag NP as carrier for the facilitated transport of olefins. To polarize the surface of Ag NP more efficiently, pbenzoquinone (p-BQ), an electron acceptor, was used to this goal, since the polymer matrix (EPR-poly(ethylene-co-propylene)) used was non-polar. The membrane selectivity achieved working with 50:50 v/v propylene/propane mixtures was 11 (Table 3). After this work, others studies have begun to explore new molecules to polarize the surface of the Ag NP, ${ }^{24,119-122}$ always aiming to improve the selectivity of separation. Figure 6 shows a schematic representation of the possible polarization mechanism of the Ag NP surface by 7,7,8,8tetracyanoquinodimethane (TCNQ).

Table 3 shows the most promising results observed for the separation of light olefin/paraffin mixtures by membranes using Ag NP. Analyzing Table 3, there is a clear evolution in the carrier properties of the Ag NP due, mainly, to the suitable choice of the polarizing agent of the NP surface, but other factors are important such as the nanoparticle concentration, its size in the polymer matrix, and its adequate dispersion along the diffusional gas pathway. Although the concentration may vary from one work to another, it is noted that a concentration higher than 30 $\mathrm{wt} \%$ of $\mathrm{Ag} \mathrm{NP}$, relative to the composite material, is required. In all works, where the facilitated transport of olefins by Ag NP with activator is verified, the NP have diameters smaller than 30 
nm. ${ }^{123}$ Therefore, Ag NP with sizes below this value can further improve the transport of the olefinic gases. Experimentally, the formation of the induced dipole on the interface between the Ag NP and the activator is checked by the X-ray photoelectron spectroscopy analysis (XPS). By changing the binding energy of the $\mathrm{d}_{5 / 2}$ and $\mathrm{d}_{3 / 2}$ silver orbitals to higher values, it is possible to verify the polarization of the NP surface. ${ }^{53,119}$ Lee et al. ${ }^{123}$ have reported an interesting study where the partial positive charge density of the surface of Ag NP was modulated by addition of TCNQ. These authors found that the amount of propylene adsorbed on the surface of the Ag NP could be correlated with the silver binding energy.

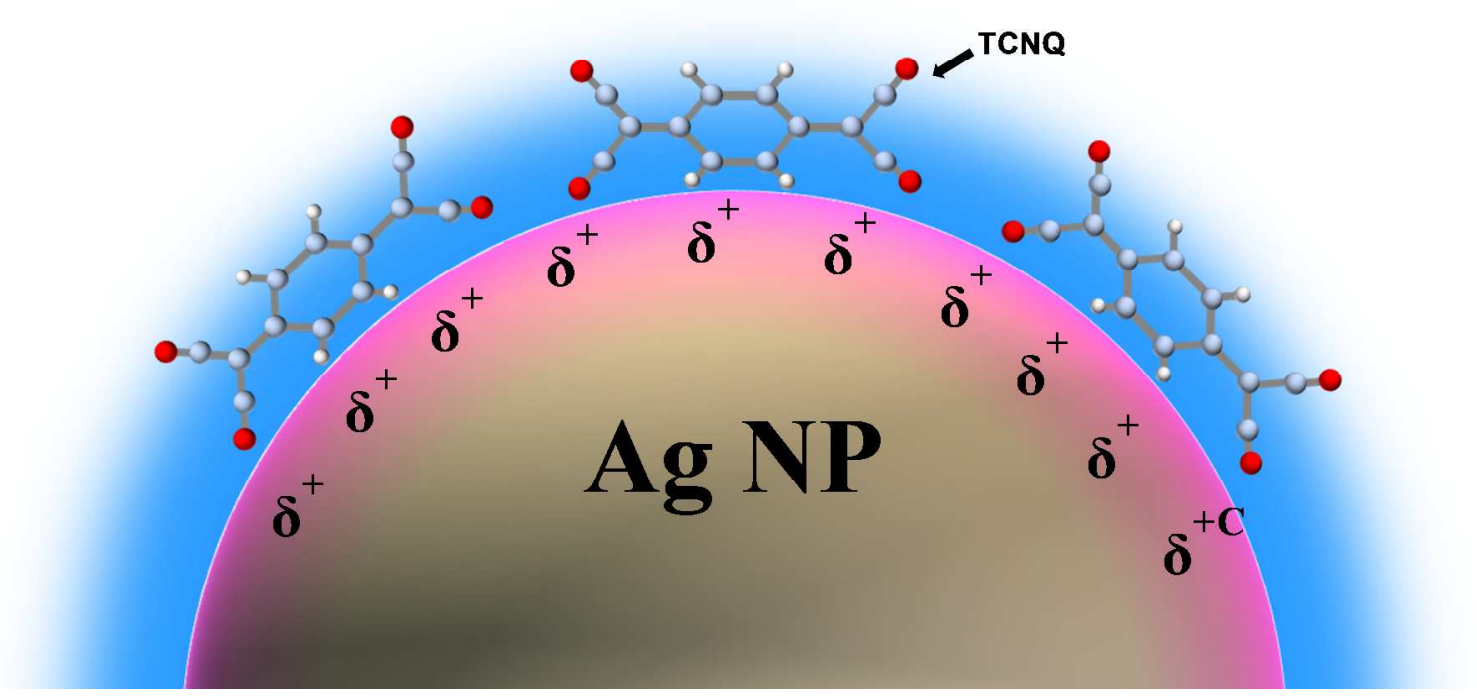

Figure 6. Schematic representation of the possible polarization mechanism of the Ag NP surface by 7,7,8,8-tetracyanoquinodimethane (TCNQ). 
Table 3. Main results of metallic nanoparticles as carriers for membrane facilitated transport of olefins.

\begin{tabular}{|c|c|c|c|c|c|c|}
\hline Polymer & $\begin{array}{l}\text { Carrier/ } \\
\text { activator } \\
\text { Fraction (\%) }\end{array}$ & $\begin{array}{l}\text { Separation } \\
\text { performance } \\
\text { (days) }\end{array}$ & Selectivity $^{\mathrm{c}}$ & $\begin{array}{l}\text { Mixed gas } \\
\text { permeance } \\
\text { (GPU) }\end{array}$ & $\begin{array}{l}\text { Olefin } \\
\text { purity } \\
(\mathrm{mol} \%)\end{array}$ & Reference \\
\hline \multirow[t]{2}{*}{ EPR } & $\mathrm{Ag} N \mathrm{~N} / \mathrm{p}-\mathrm{BQ}$ & 3.5 & 11 & 0.45 & 91.7 & In 2007 \\
\hline & $35.1 / 29.8^{\mathrm{b}}$ & & & & & Kang et al. ${ }^{53}$ \\
\hline \multirow[t]{2}{*}{ PVP } & $\mathrm{Au} N P$ & - & 22 & 1.2 & 95.7 & In 2008 \\
\hline & $81.1^{\mathrm{b}}$ & & & & & Kang et al. ${ }^{50}$ \\
\hline \multirow[t]{3}{*}{ SLM $^{*}$} & $\mathrm{Ag} \mathrm{NP} /$ & 5 & 17 & 2.7 & 94.4 & In 2008 , \\
\hline & $\mathrm{BMImBF}_{4}$ & & & & & Kang et al. ${ }^{121}$ \\
\hline & $41.2 / 58.8^{b}$ & & & & & \\
\hline \multirow[t]{2}{*}{$\mathrm{POZ}$} & Ag NP/PVP & 15 & 21 & 1.3 & 95.5 & In 2008 , \\
\hline & $29.8 / 35.1^{\mathrm{b}}$ & & & & & $\begin{array}{l}\text { Kang and } \\
\text { Kang }^{52,124}\end{array}$ \\
\hline \multirow[t]{3}{*}{ PVP } & $\mathrm{Ag} \mathrm{NP} /$ & 5.5 & 50 & 3.5 & 98.0 & In 2011, \\
\hline & TCNQ & & & & & Chae et al. ${ }^{119}$ \\
\hline & $33.1 / 0.7^{\mathrm{b}}$ & & & & & \\
\hline \multirow[t]{2}{*}{ PVP } & $\mathrm{Ag}$ NP/TTF & - & 145 & 2.5 & 99.3 & In 2014, \\
\hline & $33.3 / 33.3^{\mathrm{a}}$ & & & & & Choi et al. ${ }^{120}$ \\
\hline \multirow[t]{2}{*}{ PEO } & Ag NP/p-BQ & 10 & 10 & 15 & 90.9 & In 2014, \\
\hline & $27.8 / 2.8^{\mathrm{a}}$ & & & & & $\begin{array}{l}\text { Hong } \\
\text { al. }\end{array}$ \\
\hline \multirow[t]{3}{*}{ PVP } & $\mathrm{Ag} \mathrm{NP/}$ & 1.5 & 112 & 1.8 & 99.1 & In 2014 , \\
\hline & F4-TCNQ & & & & & Chae et al. ${ }^{122}$ \\
\hline & $48.8 / 2.4^{\mathrm{b}}$ & & & & & \\
\hline \multirow[t]{2}{*}{ PU } & $\mathrm{Ag} \mathrm{NP} /(\mathrm{OTf})^{-}$ & - & $24.4^{\mathrm{d}}$ & - & - & In 2016 , \\
\hline & $21.0 / 29.1^{\mathrm{b}}$ & & & & & $\begin{array}{l}\text { Rezende et } \\
\text { al. }{ }^{126}\end{array}$ \\
\hline
\end{tabular}

$\mathrm{a}$ - molar fraction; $\mathrm{b}$ - weight fraction; $\mathrm{c}$ - mixed gas (50:50 vol \% of propylene/propane mixture); $\mathrm{d}$ - ideal solubility selectivity of propylene/propane

*Supported liquid membranes. Support of polyester microporous membrane

EPR - poly(ethylene-co-propylene); PVP - polyvinylpyrrolidone; POZ - poly(2-ethyl-2-oxazoline); PEO poly(ethylene oxide); $\mathrm{PU}$ - polyurethane

Ag NP - silver nanoparticle; Au NP - gold nanoparticle p-BQ - p-benzoquinone; BMImBF4 - 1-butyl-3-methylimidazolium tetrafluoroborate; TCNQ - 7,7,8,8tetracyanoquinodimethane; TTF - tetrathiafulvalene; F4-TCNQ - 2,3,5,6-tetrfluoro- 7,7,8,8tetracyanoquinodimethane; (OTf) ${ }^{-}$- triflate anion. 
The membranes with Ag NP have reached higher selectivity values compared to membranes made of $\mathrm{PVP}^{119}$ with the same weight ratio of $\mathrm{Ag}^{+}$and with the advantage of being resistant to light and hydrogen gas. ${ }^{24}$ To further investigate the viability of Ag NP as promising carriers for the facilitated transport of olefins, Kang et al. ${ }^{24}$ verified the deactivation resistance against $\mathrm{C}_{2} \mathrm{H}_{2}$. Surprisingly, the NP activated with TCNQ as a polarizing agent proved to be resistant to the formation of silver acetylide. Therefore, this is an additional evidence of the superior chemical stability that the Ag NP reports compared to $\mathrm{Ag}^{+}$salts. To become even more feasible, the chemical stability of Ag NP membranes against hydrogen sulfide and other sulfur compounds needs to be investigated. Other source of instability for the separation is the inherent instability of the polarizing agents, which is few mentioned in the literature. Compounds like p-BQ, TCNQ and tetrathiafulvalene (TTF) work as electron acceptor; thus, they have a tendency of withdrawing electrons from other molecules. This feature makes polarizing agents susceptible to chemical attack similarly as it is found in $\mathrm{Ag}^{+}$cation. For instance, depending on the condition, p-BQ can easily withdraw electrons from other chemical species and consequently being transformed in hydroquinone, ${ }^{127,128}$ which is unable to polarize the surface of Ag NP. Therefore, p-BQ could be deactivated as polarizing agent by suffering a reduction process.

Other aspect that should be addressed is related to the permeance of this kind of membranes. Generally, the flux of Ag NP membranes need to be improved. For industrial application, high fluxes are required because it is necessary to reach the target high production of industrial plants. Thus, Hong et al. ${ }^{125}$ prepared a membrane of poly(ethylene oxide) with Ag NP activated by pbenzoquinone seeking out the permeance increase. The composite membrane showed a selectivity of 10 and a mixed-gas permeance of 15 GPU for 10 days, the highest permeance reported for Ag NP membranes. 
The use of Ag NP was also tested in membranes of polyurethane (ether based) (PU). Rezende et al. ${ }^{126}$ measured the sorption values of propylene and propane in Ag NP/PU membranes (Table 3), in which the Ag NP were synthesized in situ into PU matrix using UV light radiation and silver triflate $\left(\mathrm{AgCF}_{3} \mathrm{SO}_{3}\right)$ as salt precursor. It was found an ideal solubility selectivity of 24.4 in the Ag NP/PU membranes that could indicate an essential contribution of the sorption selectivity in propylene/propane separation by this kind of membrane.

\subsection{Ionic liquids for the stabilization of $\mathrm{Ag}^{+}$.}

The introduction of ionic liquids (IL) to stabilize $\mathrm{Ag}^{+}$salts in facilitated transport membranes is another alternative that the literature has reported as promising. For instance, the use of $\mathrm{POZ} / \mathrm{AgNO}_{3}$ membranes could reach stable separation performance (mixed gas permeance of 5.6 and selectivity of 32) during $150 \mathrm{~h}$ by the addition of small amount of 1-butyl-3methylimidazolium nitrate $\left(\mathrm{BMImNO}_{3}\right) .{ }^{96}$ Another example is the use of $\mathrm{PVP} / \mathrm{AgBF}_{4}$ membrane with $\mathrm{BMImNO}_{3}$ that was able to maintain a selectivity of 7.2 with 3.6 GPU nearly constant along 160 h of permeation (Table 4). ${ }^{129}$

In the search for higher stability, in the last few years, dense composite membranes incorporating ionic liquids have received much attention. ${ }^{22,112,129-132}$ In this configuration, IL/ $\mathrm{Ag}^{+}$ system is embedded in the polymer so that $\mathrm{Ag}^{+}$cations are distributed between the polymer matrix and a liquid phase entrapped inside it. This $\mathrm{Ag}^{+}$distribution through the membrane promotes the fixed and mobile carrier facilitated transport mechanisms, leading to higher permeabilities and selectivities. ${ }^{133}$ In this line, Ortiz et al. ${ }^{22,134}$ developed a material with promising characteristics for the separation of light olefin/paraffin mixtures. Previous to the material choice, a thorough investigation on the most suitable IL to form the IL/silver salt pair 
was carried out ${ }^{135,136}$. Among several pairs, 1-butyl-3-methylimidazolium tetrafluoroborate/silver tetrafluoroborate $\left(\mathrm{BMImBF}_{4} / \mathrm{AgBF}_{4}\right)$ was selected. Additionally, the fluoropolymer poly (vinylidene fluoride-co-hexafluoropropylene) (PVDF-HFP) was used as polymer matrix to avoid the potential reduction of $\mathrm{Ag}^{+}$by the polymer chain.

The results obtained with the composite films of PVDF-HFP/BMImBF $4-\mathrm{AgBF}_{4}$ behave satisfactorily providing a mixture selectivity $\mathrm{C}_{3} \mathrm{H}_{6} / \mathrm{C}_{3} \mathrm{H}_{8}=700$, and propylene permeability of 6630 Barrer or about 55 GPU in the separation process (Table 4). This remarkable performance was maintained for 10 days. The IL could stabilize the $\mathrm{Ag}^{+}$in a long-term experiment in this kind of membrane. To prove the potential of this type of material it is necessary to perform tests under the presence of the deactivating agents and verify the behavior of the composite membranes with ionic liquid against the simulated industrial operational conditions. ${ }^{22}$

On the other hand, different tests were made using thermoplastic polyurethanes (TPU)/IL membranes, but without taking into account the problems related to instability of the olefins transport. Wang et al. ${ }^{97}$ synthesized several PU membranes with different silver salt/IL pairs. The IL used contained the 1-butyl-3-methylimidazolium cation $\left(\mathrm{BMIm}^{+}\right)$. Among all membranes prepared with IL, the highest selectivity $\left(\mathrm{C}_{3} \mathrm{H}_{6} / \mathrm{C}_{3} \mathrm{H}_{8}=18.3\right)$ was found for the $\mathrm{AgBF}_{4} / \mathrm{BMImBF}_{4} / \mathrm{TPU}$ (weight fraction $10 / 20 / 70$ ) membrane. The highest olefin permeability (8400 Barrer) was observed for the $\mathrm{Ag}\left(\mathrm{Tf}_{2} \mathrm{~N}\right) / \mathrm{BMImTf}_{2} \mathrm{~N} / \mathrm{TPU}$ (weight fraction \% 10/20/70) membrane. In general, the IL enhanced the selectivity of the TPU membranes by favoring the coordination of olefin with the $\mathrm{Ag}^{+}$ions inside the dense polymeric matrix. However, the best result $\left(\mathrm{C}_{3} \mathrm{H}_{6} / \mathrm{C}_{3} \mathrm{H}_{8}=38\right.$ and 8512 Barrer) were reported for the $\mathrm{Ag}\left(\mathrm{Tf}_{2} \mathrm{~N}\right) / \mathrm{TPU}$ (weight fraction \% 10/20/70) membrane without adding IL (Table 4). 
Table 4. Results of membrane performance with ionic liquids for protection against the reduction of $\mathrm{Ag}^{+}$.

\begin{tabular}{|c|c|c|c|c|c|c|}
\hline Polymer & $\begin{array}{l}\text { Carrier/ } \\
\text { stabilizer } \\
\text { Fraction }(\%)^{a}\end{array}$ & $\begin{array}{l}\text { Separation } \\
\text { performance } \\
\text { (days) }\end{array}$ & Selectivity $^{\mathrm{b}}$ & $\begin{array}{l}\text { Mixed gas } \\
\text { permeance } \\
\text { (GPU) }\end{array}$ & $\begin{array}{l}\text { Olefin } \\
\text { purity } \\
\text { (mol\%) }\end{array}$ & Reference \\
\hline POZ & $\begin{array}{l}\mathrm{AgNO}_{3} / \\
\mathrm{BMImNO}_{3} \\
58.8 / 7.0\end{array}$ & 6 & 32 & 5.6 & 84.8 & $\begin{array}{l}\text { In 2006, } \\
\text { Kang et al. }{ }^{96}\end{array}$ \\
\hline PVP $^{f}$ & $\begin{array}{l}\mathrm{AgBF}_{4} / \\
\mathrm{BMImNO}_{3} \\
8.9 / 86.6\end{array}$ & 6.5 & 7.2 & 3.6 & 87.8 & $\begin{array}{l}\text { In } 2007 \text {, } \\
\text { Kang et al. }{ }^{129}\end{array}$ \\
\hline $\begin{array}{l}\text { PVDF- } \\
\text { HFP }\end{array}$ & $\begin{array}{l}\mathrm{AgBF}_{4} / \\
\mathrm{BMImBF}_{4} \\
60.2 / 7.8\end{array}$ & 10 & 700 & $\begin{array}{l}55^{\mathrm{d}} \\
6630^{\mathrm{e}}\end{array}$ & 99.9 & $\begin{array}{l}\text { In } 2013 \text {, } \\
\text { Fallanza et } \\
\text { al. }{ }^{22}\end{array}$ \\
\hline TPU & $\begin{array}{l}\mathrm{AgBF}_{4} / \\
\mathrm{BMImBF}_{4} \\
10 / 20\end{array}$ & - & $18.3^{\mathrm{c}}$ & $3000^{e}$ & 94.8 & $\begin{array}{l}\text { In } 2017 \text {, } \\
\text { Wang et al. }{ }^{97}\end{array}$ \\
\hline TPU & $\begin{array}{l}\operatorname{Ag}\left(\mathrm{Tf}_{2} \mathrm{~N}\right) / \\
\mathrm{BMImTf}_{2} \mathrm{~N} \\
10 / 20\end{array}$ & - & $9^{c}$ & $8398^{\mathrm{e}}$ & 90.0 & $\begin{array}{l}\text { In } 2017 \text {, } \\
\text { Wang et al. } .^{97}\end{array}$ \\
\hline TPU & $\begin{array}{l}\operatorname{Ag}\left(\mathrm{Tf}_{2} \mathrm{~N}\right) \\
30\end{array}$ & - & $38^{\mathrm{c}}$ & $8512^{\mathrm{e}}$ & 97.4 & $\begin{array}{l}\text { In 2017, } \\
\text { Wang et al. }{ }^{97}\end{array}$ \\
\hline
\end{tabular}

a - weight fraction; b - mixed gas (50:50 vol \% of propylene/propane mixture); c - tests under 2 bar transmembrane pressure; $\mathrm{d}$ - olefin permeance; $\mathrm{e}$ - olefin permeability in Barrer

POZ - poly(2-ethyl-2-oxazoline); PVP - polyvinylpyrrolidone; PVDF-HFP - poly (vinylidene fluoride-cohexafluoropropylene); TPU - thermoplastic polyurethane Elastollan ${ }^{\circledR}$

$\mathrm{BMImNO}_{3}$ - 1-butyl-3-methylimidazolium nitrate; $\mathrm{BMImBF}_{4}$ - 1-butyl-3-methylimidazolium tetrafluoroborate; $\mathrm{BMImTf}_{2} \mathrm{~N}$ - 1-butyl-3-methylimidazolium bis(tri fluoromethanesulfonyl)imide. 


\subsection{In situ regeneration using oxidizing agents.}

Merkel et al. ${ }^{28}$ have continued the research line focused on the development of polymer electrolyte membranes using polyethers which can provide a facilitated transport without the matrix humidification. This group further discussed the instability of the $\mathrm{Ag}^{+}$cation caused by deactivating agents listed in Table 2. The material used to produce the membranes was the $\operatorname{Pebax}^{\circledR} 2533$ with various levels of silver tetrafluorobate $\left(\mathrm{AgBF}_{4}\right)$. It is an elastomeric thermoplastic material composed of blocks of polyether (PE) and polyamide (PA). Specifically, the poly (ether-b-amide) used was prepared from nylon 12 and polytetramethylene oxide.

The Pebax ${ }^{\circledR} 2533 / \mathrm{AgBF}_{4}$ membranes were tested against the deactivating agents in the separation of ethylene/ethane mixtures, and as expected, the selectivity in the separation process has collapsed. However, by exposing these membranes to hydrogen peroxide vapors combined with tetrafluoroboric acid $\left(\mathrm{H}_{2} \mathrm{O}_{2} / \mathrm{HBF}_{4}\right)$ or immersing directly in a bath of $\mathrm{H}_{2} \mathrm{O}_{2} / \mathrm{HBF}_{4}$, the membranes were able to return partially or completely to the original selectivity values (Table 5).

This in situ regeneration, by using these oxidative treatments, has reversed the deactivation caused by light, $\mathrm{H}_{2}$ and $\mathrm{C}_{2} \mathrm{H}_{2}$; however, the membranes deactivated by $\mathrm{H}_{2} \mathrm{~S}$ have not shown any reversion. In the light and $\mathrm{H}_{2}$ cases, the explanation for the regeneration is that the $\mathrm{Ag}^{0}$ formed in the deactivation process is oxidized and returns to the $\mathrm{Ag}^{+}$form, becoming active again for the facilitated transport. However, the deactivation process caused by $\mathrm{H}_{2}$ seems to be more aggressive than light deactivation, since the required time to restore the same level of selectivity was longer in the case of $\mathrm{H}_{2}$ deactivation $(60 \mathrm{~h})$. According to Merkel et al., ${ }^{28}$ the understanding of the phenomenon involved in the regeneration of membranes inactivated by $\mathrm{C}_{2} \mathrm{H}_{2}$ still demands more detailed studies. Nevertheless, taking into account the chemical reaction of silver acetylide 
formation it can be thought that the regeneration is not caused by the oxidizing agent itself, but by the presence of $\mathrm{HBF}_{4}$, which shifts the equilibrium of the reduction reaction toward the $\mathrm{Ag}^{+}$ regeneration. $^{137}$

Table 5. Results of the deactivation and regeneration processes of Pebax ${ }^{\circledR} 2533+80 w^{\circ} \%$ $\mathrm{AgBF}_{4}$ membrane with original selectivity of 40 and olefin permeance of 87 GPU (adapted from Merkel et al. ${ }^{28}$ with permission from Elsevier).

\begin{tabular}{|c|c|c|c|}
\hline Deactivation process & $\begin{array}{l}\text { Selectivity }^{\mathrm{a}} \\
\text { drop }\end{array}$ & Regeneration process & $\begin{array}{l}\text { Selectivity }^{\mathrm{a}} \\
\text { regeneration }\end{array}$ \\
\hline $\begin{array}{l}\text { Membrane exposed to ambient light } \\
\text { for } 34 \text { days }\end{array}$ & $-95 \%$ & $\begin{array}{l}\text { Immersion in a } \mathrm{H}_{2} \mathrm{O}_{2} / \mathrm{HBF}_{4} \text { bath }^{\mathrm{b}} \text { for } \\
30 \mathrm{~s}\end{array}$ & $100 \%$ \\
\hline $\begin{array}{l}\text { Membrane exposed to ambient light } \\
\text { for } 34 \text { days }\end{array}$ & $-95 \%$ & $\begin{array}{l}\text { Contact with the } \mathrm{H}_{2} \mathrm{O}_{2} / \mathrm{HBF}_{4} \text { vapors } \\
\text { for } 16 \mathrm{~h}\end{array}$ & $50 \%$ \\
\hline 7 days of hydrogen permeation & $-95 \%$ & $\begin{array}{l}\text { Contact with the } \mathrm{H}_{2} \mathrm{O}_{2} / \mathrm{HBF}_{4} \text { vapors } \\
\text { for } 60 \mathrm{~h}\end{array}$ & $50 \%$ \\
\hline $\begin{array}{l}\text { Membrane exposed to } 10 \mathrm{ppm} \text { of } \\
\text { acetylene in the ethylene feed for } 5 \\
\text { days }\end{array}$ & $-85 \%$ & $\begin{array}{l}\text { Immersion in a bath of } \mathrm{H}_{2} \mathrm{O}_{2} / \mathrm{HBF}_{4} \\
\text { for } 60 \mathrm{~s}\end{array}$ & $69 \%$ \\
\hline $\begin{array}{l}\text { Membrane exposed to } 10 \mathrm{ppm} \text { of } \\
\text { hydrogen sulfide in the ethylene feed } \\
\text { for } 7 \text { days }\end{array}$ & $-92 \%$ & $\begin{array}{l}\text { Immersion in a bath of } \mathrm{H}_{2} \mathrm{O}_{2} / \mathrm{HBF}_{4} \\
\text { or contact with the } \mathrm{H}_{2} \mathrm{O}_{2} / \mathrm{HBF}_{4} \\
\text { vapors }\end{array}$ & $0 \%$ \\
\hline
\end{tabular}

$\mathrm{a}-$ mixed gas (65:35 vol \% of ethylene/ethane); $\mathrm{b}-1: 1$ mixture of $35 \mathrm{wt}^{2} \mathrm{H}_{2} \mathrm{O}_{2}$ in water and $50 \mathrm{wt} \% \mathrm{HBF}_{4}$ in water; $\mathrm{c}$ - membrane in contact with the vapor of a $1: 1 \mathrm{H}_{2} \mathrm{O}_{2} / \mathrm{HBF}_{4}$ aqueous solutions at room temperature.

From the possibility of in situ membrane regeneration, the research group believes that it will be possible to extend the service life of the membrane by applying cyclic regeneration steps, thus enabling the practical application of the membranes made of Pebax ${ }^{\circledR} 2533 / \mathrm{AgBF}_{4}$. Analyzing this proposal, it is noted that the deactivation by $\mathrm{H}_{2} \mathrm{~S}$ was not solved and the cyclic regeneration steps should be evaluated against the commercial application feasibility of the technology. 


\subsection{Current technological options.}

At the beginning of this decade, Innovative Membrane Technologies (Imtex) presented a system called Permylene ${ }^{\mathrm{TM}}$ that uses a flat sheet composite structure based on chitosan material and silver cations as facilitating agents in spiral wound membrane elements. ${ }^{138-140}$ The chitosan layer thickness is estimated to be between 2 to 4 microns. The system also uses an aqueous silver nitrate solution as continuous closed loop of hydration. This company claims that the system is able to operate with stable performance over 1000 hour. However, impurities (hydrogen, acetylene, sulfur compounds, and carbon dioxide) can affect the performance of the membrane and should be managed. More recently, in 2016, the Compact Membrane Systems (CMS) Company unveiled the separation system called Optiperm ${ }^{\mathrm{TM}}$. By this olefin/paraffin separation system, the company has claimed resistance against common poisonous agents in feed stream, including hydrogen and acetylene. ${ }^{141,142}$ Probably, the reason of stability is the membrane based on highly fluorinated polymers, which are extremely resistant to chemical and thermal harsh conditions. ${ }^{23}$ To prepare the membrane, $\mathrm{Ag}^{+}$cations are incorporated to the polymer matrix by ion-exchange with the $\mathrm{H}^{+}$from sulfonic groups of the fluorinate polymer. Unlike previous works, ${ }^{27,75,78,80}$ in which the membrane was immersed in a silver salt aqueous solution to achieve ion-exchange, in this case the polymer and the $\mathrm{Ag}^{+}$salt are solubilized in the same solvent. After, the solution is casted to form a polymeric film called silver ionomer, responsible for the facilitated transport of olefins. $^{23}$

As in any typical structure of thin film composite membrane used for industrial gas separations, the selective layer has the task of distinguishing the molecules to be separated and it should be thin $(0.1-1 \mu \mathrm{m})$ to provide high permeances. A thin layer does not have enough mechanical strength and it is necessary to deposit it onto the surface of a porous support (150- 
$200 \mu \mathrm{m})$ with negligible mass transport resistance. In addition, another high diffusion layer can be added to protect the selective layer and plug any defects eventually present. This protective layer prevents damage during the manipulation of the membrane and protects the exposed surface of the selective layer from contaminants present in the stream to be separated. ${ }^{143,144}$

In the Optiperm ${ }^{\mathrm{TM}}$ system, ${ }^{23}$ the high diffusion layer is made of glassy polymer based on perfluoroether and chlorotrifluoroethylene groups, which are resistant against oxidation by the $\mathrm{Ag}^{+}$cation. For the selective layer, amorphous perfluoropolymers are used to maximize $\mathrm{Ag}^{+}$ cation stability. The fluoropolymer inertness and the protection offered by the protective layer are responsible for the resistance against poisonous/deactivating agents.

According to the information reported in a patent assigned to $\mathrm{CMS},{ }^{23}$ the best results (Table 6) were achieved by using the following materials for the membrane layers. The high diffusion layers are composed of Teflon ${ }^{\circledR}$ AF 2400, a copolymer with $83 \%$ (molar percentage) of perfluoro(2,2-dimethyl-1,3-dioxole) (PDD) and 17\% of tetrafluoroethylene. The porous support is made of PAN350, an ultrafilter made from polyacrylonitrile. Two selective layers with the same amount of $\mathrm{AgNO}_{3}$ are tested. One layer has higher permeance and lower selectivity (selective layer 1) and the second one has lower productivity and higher selectivity (selective layer 2). The selective layer 1 is composed by a silver ionomer of sulfonic acid based on the PDD/VF (vinyl fluoride)/PPSF (perfluoro sulfonylfluorideethylvinyl ether) terpolymer $\left(\mathrm{T}_{\mathrm{g}} 58\right.$ ${ }^{\circ} \mathrm{C}$ ). The selective layer 2 is made of the Aquivion®D79-25BS, ${ }^{113}$ a perfluorosulfonic acid polymer made from perfluorosulfonylfluoridevinyl ether monomer. The patent, doesn't report information related to long-term stability and tests of resistance against poisonous agents. The permeation tests were conducted using humidification of the feed stream and $\mathrm{N}_{2}$ as a sweep gas. 
Regarding the humidification need issue related to the ion-exchange membranes, ${ }^{145}$ Feiring et al. ${ }^{146}$ tested different configurations to provide the required moisture in highly fluorinated silver ionomer membranes. In the configuration 1 , they humidified the sweep gas $\left(\mathrm{N}_{2}\right)$ and the feed mixture. In the configuration 2 , the feed was dried, and the sweep gas was a water vapor under vacuum. Finally, the configuration 3 employed a dried feed and vacuum. As expected, the best results corresponded to configuration 1. Surprisingly, the configuration 2 and 3 provided equivalent high olefin/paraffin selectivity but $30 \%$ and $60 \%$ smaller olefin permeance respectively. The presence of the inert sweep gas in the permeate stream implies a further separation step. Thus, configuration 2, which does not use the $\mathrm{N}_{2}$ as sweep gas, shows an advantage since the permeate stream only has moisture, olefin; and eventual small amount of paraffin. A subsequent drying stage may be considered in the separation train, but it seems an easier task than removing the inert gas from the outlet stream of the membrane unit.

Table 6. Performance of facilitated transport membranes based on highly fluorinated polymers after the results of Majumdar et al. (2016). ${ }^{23}$

\begin{tabular}{|c|c|c|c|c|}
\hline Polymer & $\begin{array}{l}\text { Carrier } \\
\text { Fraction }(\%)^{\mathrm{a}}\end{array}$ & Selectivity $^{\mathrm{b}}$ & $\begin{array}{l}\text { Olefin } \\
\text { permeance } \\
\text { (GPU) }\end{array}$ & $\begin{array}{l}\text { Olefin purity } \\
\text { (mol\%) }\end{array}$ \\
\hline \multirow[t]{2}{*}{ (PDD/VF/PPSF) } & $\mathrm{AgNO}_{3}$ & 95.7 & 276 & 96.0 \\
\hline & $16.7^{\mathrm{b}}$ & & & \\
\hline \multirow[t]{2}{*}{ Aquivion ${ }^{\circledR} \mathrm{D} 79-25 \mathrm{BS}$} & $\mathrm{AgNO}_{3}$ & 52.1 & 311 & 92.9 \\
\hline & $16.7^{\mathrm{b}}$ & & & \\
\hline
\end{tabular}




\section{SUMMARY AND CONCLUSIONS}

The global demand of light olefins has experienced a significant growth related to the increasing demand of different polymers over the last decades. The principal process to produce olefins is the naphtha steam cracking process, the most energy intensive process in the petrochemical industry. In an attempt to save energy in the process, some alternatives have been proposed to replace or integrate with the current cryogenic distillation separation of olefins and paraffins. Among several technologies, facilitated transport membranes have stood out owing to the combination of high selectivity and permeance. However, to be used in the industrial separation, some instability issues should be considered.

$\mathrm{The} \mathrm{Ag}^{+}$cation, the main carrier for the facilitated transport membrane, suffers deactivation by poisonous agents present in the gaseous stream to be separated. Even without the presence of deactivating agents, the $\mathrm{Ag}^{+}$cation can be reduced by the chemical environmental of the polymer matrix from which the membrane is made. After achieving superior performance by using silver salts dissolved or dispersed in polymer matrix, the current arduous task is to maintain the selectivity in long-term separation process. To attain this goal, some clever alternatives have been proposed to overcome the hurdle.

By adding small amounts of $\mathrm{HBF}_{4}$ or non-ionic surfactants, it is possible to confer certain stability to $\mathrm{Ag}^{+}$cation. In addition, the introduction of $\mathrm{Al}\left(\mathrm{NO}_{3}\right)_{3}$ in electrolyte membranes can weaken the interaction between the functional group of the polymer and the $\mathrm{Ag}^{+}$salt, providing a more stable chemical environment to the $\mathrm{Ag}^{+}$. A remarkable result was reached with a $\mathrm{POZ} / \mathrm{AgBF}_{4} / \mathrm{Al}\left(\mathrm{NO}_{3}\right)_{3}$ membrane. The selectivity was maintained during 14 days. The use of another interesting carrier, $\mathrm{Ag} \mathrm{NP}$, overcome the problem related to the reduction of $\mathrm{Ag}^{+}$. To be useful, the Ag NP should be activated by a suitable polarizing agent. Experimental tests showed 
the resistance of Ag NP against acetylene, which is one of the poisonous agents. Therefore, Ag NP reveal higher resistance compared to $\mathrm{Ag}^{+}$. The best results reached by $\mathrm{Ag} \mathrm{NP}$ composite membranes achieved a selectivity of 10 and a mixed-gas permeance of 15 GPU for 10 days.

To avoid the $\mathrm{Ag}^{+}$cation reduction inside the polymer matrix, more inert polymers have begun to be applied as a host matrix to silver salts. Specially fluoropolymers, which are well known by their intrinsic inertness, have been used as material to the preparation of $\mathrm{Ag}^{+}$facilitated transport membranes. A PVDF-HFP matrix was used for hosting a system of $\mathrm{AgBF}_{4} / \mathrm{BMImBF}_{4}$. IL have been demonstrated as another type of agents able to stabilize $\mathrm{Ag}^{+}$against reduction. Joining these features, a membrane of PVDF-HFP/BMImBF $-\mathrm{AgBF}_{4}$ reported a mixture selectivity of 700 and propylene permeability of 6630 Barrer (about 55 GPU) in a 10 days separation test. Claiming resistance against common poisonous agents in the feed stream, a thin film composite membrane based on a highly fluorinated polymer was developed by Compact Membrane Systems Company. Beyond the intrinsic inertness of the membrane material, additional protection arises from the configuration of the composite membrane. A thin separation layer composed by fluorinated silver ionomer, which is responsible for the facilitated transport of olefins, is between two high diffusion protective layers. This configuration seems to avoid the poisoning of the $\mathrm{Ag}^{+}$ cation that are ionic bonded in the ion-exchange polymer; however, the membrane humidification dependence was not solved. If the problems related to poisoning are still present in the membrane process, other alternative is to try an in situ regeneration using vapor of the oxidizing system $\left(\mathrm{H}_{2} \mathrm{O}_{2} / \mathrm{HBF}_{4}\right)$ to recover the separation performance and extend the service life of the membrane.

Most of the results reported in the literature didn't consider the presence of poisonous agents in the permeation experiments. The main concern is still the stability of $\mathrm{Ag}^{+}$inside the polymer 
matrix, but it seems that this challenge has started to be overcome using stabilizing agents and inert polymer matrix. Issues related to the plasticization effects are not yet a problem discussed intensively by the works concentrated in the facilitated transport membrane for the olefin/paraffin separation. Probably, the future efforts will be dedicated to understand deeply the problems regarding the poisonous agents, trying to figure out a more robust solution. Due to the lower performance required and milder condition operation, the initial commercial application of the membrane technology to olefin/paraffin separation could be in the vent streams of some kinds of petrochemical reactors. This application could make a step forward in the use of commercial olefin/paraffin membrane units before the challenging task aimed to replace the distillation unit in the steam cracking process or in the FCC off-gas streams. 


\section{ACKNOWLEDGMENTS}

The authors thank the Brazilian Federal Agency for Support and Evaluation of Graduate Education - CAPES (PDSE Grant - 88881.134232/2016-01) and the Spanish Ministry of Economy, Industry and Competitiveness (CTQ2015-66078-R and CTQ2016-75158-R projects, Spain-FEDER 2014-2020) for financial support. 


\section{REFERENCES}

(1) Petrochemicals Europe. Petrochemicals Make Things Happen; 2017.

(2) Nakayama, N. Global Supply and Demand of Petrochemical Products Relied on LPG as Feedstock; International LP Gas Seminar: Tokyo, 2017.

(3) Amghizar, I.; Vandewalle, L. A.; Van Geem, K. M.; Marin, G. B. New Trends in Olefin Production. Engineering 2017, 3 (2), 171-178.

(4) Foster, J. Can Shale Gas Save the Naphtha Crackers? Platts special report: Petrochemicals. 2013, p 3.

(5) Brooks, R. E. Modeling the North American Market for Natural Gas Liquids; 32nd US Association of Energy and Economics (USAEE) Conference: Anchorage, 2013.

(6) Ren, T.; Patel, M.; Blok, K. Olefins from Conventional and Heavy Feedstocks: Energy Use in Steam Cracking and Alternative Processes. Energy 2006, 31 (4), 425-451.

(7) Chuapet, W.; Limphitakphong, N.; Tantisattayakul, T.; Kanchanapiya, P.; Chavalparit, O. A Study of Energy Intensity and Carbon Intensity from Olefin Plants in Thailand. MATEC Web Conf. 2016, 68, 6-10.

(8) Zimmermann, H.; Walzl, R. Ethylene. In Ullmann's Encyclopedia of Industrial Chemistry; Wiley-VCH: Weinheim, 2012; Vol. 13, pp 465-529.

(9) Falqi, F. H. The Miracle of Petrochemicals. Olefins Industry: An in-Depth Look at SteamCrackers; Universal-Publishers Boca Raton, Ed.; Florida, 2009.

(10) Xu, L.; Rungta, M.; Brayden, M. K.; Martinez, M. V.; Stears, B. A.; Barbay, G. A.; 
Koros, W. J. Olefins-Selective Asymmetric Carbon Molecular Sieve Hollow Fiber Membranes for Hybrid Membrane-Distillation Processes for Olefin/Paraffin Separations. J. Memb. Sci. 2012, 423-424, 314-323.

(11) Baker, R. W.; Low, B. T. Gas Separation Membrane Materials: A Perspective. Macromolecules 2014, 47 (20), 6999-7013.

(12) Park, J.; Kim, K.; Shin, J.-W.; Tak, K.; Park, Y.-K. Performance Study of Multistage Membrane and Hybrid Distillation Processes for Propylene/Propane Separation. Can. J. Chem. Eng. 2017, 95 (12), 2390-2397.

(13) Safarik, D. J.; Eldridge, R. B. Olefin/Paraffin Separations by Reactive Absorption: A Review. Ind. Eng. Chem. Res. 1998, 37 (7), 2571-2581.

(14) Bernardo, P.; Drioli, E.; Golemme, G. Membrane Gas Separation: A Review/State of the Art. Ind. Eng. Chem. Res. 2009, 48 (10), 4638-4663.

(15) Pozun, Z. D.; Henkelman, G. A Model to Optimize the Selectivity of Gas Separation in Membranes. J. Memb. Sci. 2010, 364 (1-2), 9-16.

(16) Zarca, R.; Ortiz, A.; Gorri, D.; Biegler, L. T.; Ortiz, I. Optimized Distillation Coupled With State-of-the-Art Membranes for Propylene Purification. J. Memb. Sci. 2018, 556, $321-328$.

(17) Amedi, H. R.; Aghajani, M. Economic Estimation of Various Membranes and Distillation for Propylene and Propane Separation. Ind. Eng. Chem. Res. 2018, 57 (12), 4366-4376.

(18) Antonio, M. R.; Tsou, D. T. Silver Ion Coordination in Membranes for Facilitated Olefin Transport. Ind. Eng. Chem. Res. 1993, 32 (2), 273-278. 
(19) Li, Y.; Wang, S.; He, G.; Wu, H.; Pan, F.; Jiang, Z. Facilitated Transport of Small Molecules and Ions for Energy-Efficient Membranes. Chem. Soc. Rev. 2015, 44 (1), 103118.

(20) Ho, W. S.; Dalrymple, D. C. Facilitated Transport of Olefins in $\mathrm{Ag}^{+}$-Containing Polymer Membranes. J. Memb. Sci. 1994, 91 (1-2), 13-25.

(21) Pollo, L. D.; Duarte, L. T.; Anacleto, M.; Habert, A. C.; Borges, C. P. Polymeric Membranes Containing Silver Salts for Propylene/Propane Separation. Brazilian J. Chem. Eng. 2012, 29 (2), 307-314.

(22) Fallanza, M.; Ortiz, A.; Gorri, D.; Ortiz, I. Polymer-Ionic Liquid Composite Membranes for Propane/Propylene Separation by Facilitated Transport. J. Memb. Sci. 2013, 444, 164172.

(23) Majumdar, S.; Koizumi, Y.; Shangguan, N.; Feirring, A. E. Thin Film Composite Membranes for Separation of Alkenes from Alkanes. W.O. Patent 2016/182887 A1, November 17, 2016.

(24) Kim, Y. R.; Lee, J. H.; Choi, H.; Cho, W.; Kang, Y. S. Chemical Stability of Olefin Carrier Based on Silver Cations and Metallic Silver Nanoparticles against the Formation of Silver Acetylide for Facilitated Transport Membranes. J. Memb. Sci. 2014, 463, 11-16.

(25) Lee, U.; Kim, J.; Chae, I. S.; Han, C. Techno-Economic Feasibility Study of Membrane Based Propane/Propylene Separation Process. Chem. Eng. Process. Process Intensif. 2017, 119, 62-72.

(26) Park, Y. S.; Chun, S.; Kang, Y. S.; Kang, S. W. Durable Poly(Vinyl 
Alcohol)/AgBF4/Al(NO3)3 Complex Membrane with High Permeance for Propylene/Propane Separation. Sep. Purif. Technol. 2017, 174 (3), 39-43.

(27) Faiz, R.; Li, K. Olefin/Paraffin Separation Using Membrane Based Facilitated Transport/Chemical Absorption Techniques. Chem. Eng. Sci. 2012, 73, 261-284.

(28) Merkel, T. C.; Blanc, R.; Ciobanu, I.; Firat, B.; Suwarlim, A.; Zeid, J. Silver Salt Facilitated Transport Membranes for Olefin/Paraffin Separations: Carrier Instability and a Novel Regeneration Method. J. Memb. Sci. 2013, 447, 177-189.

(29) Akah, A.; Al-Ghrami, M. Maximizing Propylene Production via FCC Technology. Appl. Petrochemical Res. 2015, 1-16.

(30) European Commission. Reference Document on Best Available Techniques in the Large Volume Organic Chemical Industry February 2003. Integr. Pollut. Prev. Control 2003, 1 (February), 267-289.

(31) Merkel, T.; Blanc, R.; Zeid, J.; Suwarlim, A.; Firat, B.; Wijmans, H.; Asaro, M.; Greene, M. Separation of Olefin / Paraffin Mixtures with Carrier Facilitated Membranes; Report DE-FC36-04GO14151, U.S. Department of Energy, 2007.

(32) Liskey, C. W.; Liu, C.; Tran, H. Q. Polyimide Membranes with Very High Separation Performance for Olefin/Paraffin Separation. U.S. Patent 2015/0328594 A1, November 19, 2015.

(33) Baker, R. W. Future Directions of Membrane Gas Separation Technology. Ind. Eng. Chem. Res. 2002, 41 (6), 1393-1411.

(34) Staudt-Bickel, C.; Koros, W. J. Olefin/Paraffin Gas Separations with 6FDA-Based 
Polyimide Membranes. J. Memb. Sci. 2000, 170 (2), 205-214.

(35) Giannakopoulos, I. G.; Nikolakis, V. Separation of Propylene/Propane Mixtures Using Faujasite-Type Zeolite Membranes. Ind. Eng. Chem. Res. 2005, 44 (1), 226-230.

(36) Nikolakis, V.; Xomeritakis, G.; Abibi, A.; Dickson, M.; Tsapatsis, M.; Vlachos, D. G. Growth of a Faujasite-Type Zeolite Membrane and Its Application in the Separation of Saturated/Unsaturated Hydrocarbon Mixtures. J. Memb. Sci. 2001, 184 (2), 209-219.

(37) Liu, D.; Ma, X.; Xi, H.; Lin, Y. S. Gas Transport Properties and Propylene/Propane Separation Characteristics of ZIF-8 Membranes. J. Memb. Sci. 2014, 451, 85-93.

(38) Zhang, C.; Lively, R. P.; Zhang, K.; Johnson, J. R.; Karvan, O.; Koros, W. J. Unexpected Molecular Sieving Properties of Zeolitic Imidazolate Framework-8. J. Phys. Chem. Lett. 2012, 3 (16), 2130-2134.

(39) Kwon, H. T.; Jeong, H.-K. In Situ Synthesis of Thin Zeolitic-Imidazolate Framework ZIF-8 Membranes Exhibiting Exceptionally High Propylene/Propane Separation. J. Am. Chem. Soc. 2013, 135 (29), 10763-10768.

(40) Kwon, H. T.; Jeong, H.-K. Highly Propylene-Selective Supported Zeolite-Imidazolate Framework (ZIF-8) Membranes Synthesized by Rapid Microwave-Assisted Seeding and Secondary Growth. Chem. Commun. 2013, 49 (37), 3854.

(41) Pan, Y.; Li, T.; Lestari, G.; Lai, Z. Effective Separation of Propylene/Propane Binary Mixtures by ZIF-8 Membranes. J. Memb. Sci. 2012, 390-391, 93-98.

(42) Liu, J.; Goss, J. M.; Calverley, E. M.; Beyer, D. E. Separation of Gases via Carbonized Vinylidene Chloride Copolymer Gas Separation Membranes and Process for the 
Preparation of the Membranes. W.O. Patent 2017/160815 A1, September 21, 2017.

(43) Liu, J.; Calverley, E. M.; McAdon, M. H.; Goss, J. M.; Liu, Y.; Andrews, K. C.; Wolford, T. D.; Beyer, D. E.; Han, C. S.; Anaya, D. A.; et al. New Carbon Molecular Sieves for Propylene/Propane Separation with High Working Capacity and Separation Factor. Carbon 2017, 123, 273-282.

(44) Koros, W. J.; Ma, Y. H.; Shimidzu, T. Terminology for Membranes and Membrane Processes. Pure Appl. Chem. 1996, 68 (7), 1479-1489.

(45) Kim, J. H.; Lee, D. H.; Won, J.; Jinnai, H.; Kang, Y. S. The Structural Transitions of PiComplexes of Poly(Styrene-b-Butadiene-b-Styrene) Block Copolymers with Silver Salts and Their Relation to Facilitated Olefin Transport. J. Memb. Sci. 2006, 281, 369-376.

(46) Bai, S.; Sridhar, S.; Khan, A. . Metal-Ion Mediated Separation of Propylene from Propane Using PPO Membranes. J. Memb. Sci. 1998, 147 (1), 131-139.

(47) Krol, J. J.; Boerrigter, M.; Koops, G. H. Polyimide Hollow Fiber Gas Separation Membranes: Preparation and the Suppression of Plasticization in Propane/Propylene Environments. J. Memb. Sci. 2001, 184 (2), 275-286.

(48) Okamoto, K.; Noborio, K.; Hao, J.; Tanaka, K.; Kita, H. Permeation and Separation Properties of Polyimide Membranes to 1,3-Butadiene and n-Butane. J. Memb. Sci. 1997, $134(2), 171-179$.

(49) Burns, R. L.; Koros, W. J. Defining the Challenges for C3H6/C3H8 Separation Using Polymeric Membranes. J. Memb. Sci. 2003, 211 (2), 299-309.

(50) Kang, S. W.; Hong, J.; Park, J. H.; Mun, S. H.; Kim, J. H.; Cho, J.; Char, K.; Kang, Y. S. 
Nanocomposite Membranes Containing Positively Polarized Gold Nanoparticles for Facilitated Olefin Transport. J. Memb. Sci. 2008, 321 (1), 90-93.

(51) Kim, J. H.; Min, B. R.; Won, J.; Joo, S. H.; Kim, H. S.; Kang, Y. S. Role of Polymer Matrix in Polymer/Silver Complexes for Structure, Interactions, and Facilitated Olefin Transport. Macromolecules 2003, 36 (16), 6183-6188.

(52) Kang, S. W.; Kang, Y. S. Silver Nanoparticles Stabilized by Crosslinked Poly(Vinyl Pyrrolidone) and Its Application for Facilitated Olefin Transport. J. Colloid Interface Sci. 2011, 353 (1), 83-86.

(53) Kang, Y. S.; Kang, S. W.; Kim, H.; Kim, J. H.; Won, J.; Kim, C. K.; Char, K. Interaction with Olefins of the Partially Polarized Surface of Silver Nanoparticles Activated by PBenzoquinone and Its Implications for Facilitated Olefin Transport. Adv. Mater. 2007, 19 (3), 475-479.

(54) Dewar, M. J. S. A Review of the P-Complex Theory. Bull. la Socie'te' Chim. 1951, 18, C71-9.

(55) Chatt, J., Duncanson, L. A. Olefin Co-Ordination Compounds. Part III. Infrared Spectra and Structure: Attempted Preparation of Acetylene Complexes. J. Chem. Soc. 1953, 2939.

(56) Miessler, G. L.; Fischer, P. J.; Tarr, D. A. Inorganic Chemistry, 5th ed.; Pearson: Upper Saddle Rive, NJ, 2014.

(57) Cotton, F. A.; Wilkinson, G.; Murillo, C. A.; Bochmann, M. Advanced Inorganic Chemistry, 6th ed.; Wiley-Interscience, Ed.; New York, 1999.

(58) Eldridge, R. B. Olefin/Paraffin Separation Technology: A Review. Ind. Eng. Chem. Res. 
1993, 32, 2208-2212.

(59) Scholander, P. F. Oxygen Transport through Hemoglobin Solutions. Science 1960, 131, 585.

(60) Baker, R. W. Membrane Technology and Applications; Chapter 8: Gas Separation; John Wiley \& Sons, Ltd: Chichester, 2004; pp 301-353.

(61) Kang, Y. S.; Won, J. O.; Jung, B. S.; Park, H. H.; Oh, S. G. Solid State Polymer Electrolyte Facilitated Transport Membranes Containing Surfactants. U.S. Patent 6,645,276 B2 November 11, 2003.

(62) Kim, J. H.; Kang, Y. S.; Won, J. Silver Polymer Electrolyte Membranes for Facilitated Olefint Transport: Carrier Properties, Transport Mechanism and Separation Performance. Macromol. Res. 2004, 12 (2), 145-155.

(63) Bryan, P. F. Removal of Propylene from Fuel-Grade Propane. Sep. Purif. Rev. 2004, 33 (2), 157-182.

(64) Sun, Y.; Bi, H.; Dou, H.; Yang, H.; Huang, Z.; Wang, B.; Deng, R.; Zhang, L. A Novel Copper(I)-Based Supported Ionic Liquid Membrane with High Permeability for Ethylene/Ethane Separation. Ind. Eng. Chem. Res. 2017, 56 (3), 741-749.

(65) Steigelmann, E. F.; Hughes, R. D. Process for Separation of Unsaturated Hydrocarbons. U.S. Patent 3,758,603, September 11, 1973.

(66) Hughes, R. D.; Mahoney, J. A.; Steigelmann, E. F. Olefin Separation by Facilitated Transport Membranes. In Recent Developments in Separation Science; Li, N. N., Calo, J. M., Eds.; CRC Press: Boca Raton, 1986; pp 173-196. 
(67) Duan, S.; Ito, A.; Ohkawa, A. Separation of Propylene/Propane Mixture by a Supported Liquid Membrane Containing Triethylene Glycol and a Silver Salt. J. Memb. Sci. 2003, $215(1-2), 53-60$.

(68) Fallanza, M.; Ortiz, A.; Gorri, D.; Ortiz, I. Experimental Study of the Separation of Propane/Propylene Mixtures by Supported Ionic Liquid Membranes Containing $\mathrm{Ag}^{+}-$ RTILs as Carrier. Sep. Purif. Technol. 2012, 97, 83-89.

(69) Pitsch, F.; Krull, F. F.; Agel, F.; Schulz, P.; Wasserscheid, P.; Melin, T.; Wessling, M. An Adaptive Self-Healing Ionic Liquid Nanocomposite Membrane for Olefin-Paraffin Separations. Adv. Mater. 2012, 24 (31), 4306-4310.

(70) Kárászová, M.; Kacirková, M.; Friess, K.; Izák, P. Progress in Separation of Gases by Permeation and Liquids by Pervaporation Using Ionic Liquids: A Review. Sep. Purif. Technol. 2014, 132, 93-101.

(71) Teramoto, M.; Matsuyama, H.; Yamashiro, T.; Katayama, Y. Separation of Ethylene from Ethane by Supported Liquid Membranes Containing Silver Nitrate as a Carrier. J. Chem. Eng. Japan 1986, 19 (5), 419-424.

(72) Ravanchi, M. T.; Kaghazchi, T.; Kargari, A. Facilitated Transport Separation of Propylene-Propane: Experimental and Modeling Study. Chem. Eng. Process. Process Intensif. 2010, 49 (3), 235-244.

(73) Ravanchi, M. T.; Kaghazchi, T.; Kargari, A. Supported Liquid Membrane Separation of Propylene-Propane Mixtures Using a Metal Ion Carrier. Desalination 2010, 250 (1), 130135. 
(74) Oliver H. Leblanc; William J. Ward; Stephen L. Matson; Shiro G. Kimura. Facilitated Transport in Ion-Exchange Membranes. J. Memb. Sci. 1980, 6, 339-343.

(75) Eriksen, O. I.; Aksnes, E.; Dahl, I. M. Facilitated Transport of Ethene through Nafion Membranes. Part II. Glycerine Treated, Water Swollen Membranes. J. Memb. Sci. 1993, $85(1), 99-106$.

(76) Eriksen, O. I.; Aksnes, E.; Dahl, I. M. Facilitated Transport of Ethene through Nafion Membranes. Part I. Water Swollen Membranes. J. Memb. Sci. 1993, 85 (1), 89-97.

(77) Rabago, R.; Noble, R. D.; Koval, C. A. Effects of Incorporation of Fluorocarbon and Hydrocarbon Surfactants into Perfluorosulfonic Acid (Nafion) Membranes. Chem. Mater. 1994, $6(7), 947-951$.

(78) Sungpet, A.; Way, J. D.; Thoen, P. M.; Dorgan, J. R. Reactive Polymer Membranes for Ethylene/Ethane Separation. J. Memb. Sci. 1997, 136 (1-2), 111-120.

(79) Yamaguchi, T.; Baertsch, C.; Koval, C. A.; Noble, R. D.; Bowman, C. N. Olefin Separation Using Silver Impregnated Ion-Exchange Membranes and Silver Salt/Polymer Blend Membranes. J. Memb. Sci. 1996, 117 (1-2), 151-161.

(80) Thoen, P. M.; Noble, R. D.; Koval, C. A. Unexpectedly Large Selectivities for Olefin Separations Utilizing Silver Ion in Ion-Exchange Membranes. J. Phys. Chem. 1994, 98 (4), 1262-1269.

(81) Koval, C.; Bryant, D.; Engelhardt, H.; Manley, D.; Rabago, R.; Thoen, P.; Noble, R. Facilitated Transport of Unsaturated Hydrocarbons in Perfluorosulfonic Acid (Nafion) Membranes. In Chemical Separations with Liquid Membranes; Bartsch, R.; Way, J. D., 
Eds.; ACS Symposium Series; American Chemical Society: Washington, DC, 1996; Vol. 642, pp 286-302.

(82) Liu, L.; Feng, X.; Chakma, A. Unusual Behavior of Poly(Ethylene Oxide)/AgBF 4 Polymer Electrolyte Membranes for Olefin-Paraffin Separation. Sep. Purif. Technol. 2004, $38(3), 255-263$.

(83) Pinnau, I.; Toy, L. G. Solid Polymer Electrolyte Composite Membranes for Olefin/Paraffin Separation. J. Memb. Sci. 2001, 184 (1), 39-48.

(84) Kim, J. H.; Min, B. R.; Kim, C. K.; Won, J. New Insights into the Coordination Mode of Silver Ions Dissolved in Poly ( 2-Ethyl-2-Oxazoline ) and Its Relation to Facilitated Olefin. Macromolecules 2002, 35, 5250-5255.

(85) Sunderrajan, S.; Freeman, B. D.; Hall, C. K.; Pinnau, I. Propane and Propylene Sorption in Solid Polymer Electrolytes Based on Poly(Ethylene Oxide) and Silver Salts. J. Memb. Sci. 2001, $182(1-2), 1-12$.

(86) Morisato, A.; He, Z.; Pinnau, I.; Merkel, T. C. Transport Properties of PA12PTMO/AgBF4 Solid Polymer Electrolyte Membranes for Olefin/Paraffin Separation. Desalination 2002, 145 (1), 347-351.

(87) Merkel, T. C.; He, Z.; Morisato, A.; Pinnau, I. Olefin/Paraffin Solubility in a Solid Polymer Electrolyte Membrane. Chem. Commun. 2003, (13), 1596 -1597.

(88) Kim, J. H.; Kang, S. W.; Kang, Y. S. Threshold Silver Concentration for Facilitated Olefin Transport in Polymer/Silver Salt Membranes. J. Polym. Res. 2012, 19 (1), 9753.

(89) Kim, J. H.; Min, B. R.; Kim, H. S.; Won, J.; Kang, Y. S. Facilitated Transport of Ethylene 
across Polymer Membranes Containing Silver Salt: Effect of HBF4 on the Photoreduction of Silver Ions. J. Memb. Sci. 2003, 212 (1), 283-288.

(90) Kim, J. H.; Won, J.; Kang, Y. S. Olefin-Induced Dissolution of Silver Salts Physically Dispersed in Inert Polymers and Their Application to Olefin/Paraffin Separation. J. Memb. Sci. 2004, 241 (2), 403-407.

(91) Kang, Y. S.; Kim, J. H.; Won, J.; Kim, H. S. Solid-State Facilitated Transport Membranes for Separation of Olefins / Paraffins and Oxygen / Nitrogen. In Materials Science of Membranes for Gas and Vapor Separation; Yampolskii, Y., Pinnau, I., Freeman, B., Eds.; John Wiley \& Sons, Ltd.: Chichester, 2006; pp 391-410.

(92) Kim, J. H.; Won, J.; Kang, Y. S. Silver Polymer Electrolytes by $\pi$-Complexation of Silver Ions with Polymer Containing $\mathrm{C}=\mathrm{C}$ Bond and Their Application to Facilitated Olefin Transport Membranes. J. Memb. Sci. 2004, 237 (1-2), 199-202.

(93) Kim, J. H.; Min, B. R.; Won, J.; Kang, Y. S. Revelation of Facilitated Olefin Transport through Silver-Polymer Complex Membranes Using Anion Complexation. Macromolecules 2003, 36 (12), 4577-4581.

(94) Kim, J. H.; Min, B. R.; Won, J.; Kang, Y. S. Complexation Mechanism of Olefin with Silver Ions Dissolved in a Polymer Matrix and Its Effect on Facilitated Olefin Transport. Chem. Eur. J. 2002, 8 (3), 650-654.

(95) Kim, J. H.; Min, B. R.; Kim, C. K.; Won, J.; Kang, Y. S. Spectroscopic Interpretation of Silver Ion Complexation with Propylene in Silver Polymer Electrolytes. J. Phys. Chem. B 2002, 106 (10), 2786-2790. 
(96) Kang, S. W.; Char, K.; Kim, J. H.; Kim, C. K.; Kang, Y. S. Control of Ionic Interactions in Silver Salt-Polymer Complexes with Ionic Liquids: Implications for Facilitated Olefin Transport. Chem. Mater. 2006, 18 (7), 1789-1794.

(97) Wang, Y.; Goh, T. Y.; Goodrich, P.; Atilhan, M.; Khraisheh, M.; Rooney, D.; Thompson, J.; Jacquemin, J. Impact of Ionic Liquids on Silver Thermoplastic Polyurethane Composite Membranes for Propane/Propylene Separation. Arab. J. Chem. 2017, in press (http://dx.doi.org/10.1016/j.arabjc.2017.05.008)

(98) Duarte, L. T.; Habert, A. C.; Borges, C. P. Preparation and Morphological Characterization of Polyurethane/Polyethersulfone Composite Membranes. Desalination 2002, $145(1-3), 53-59$.

(99) Ferraz, H. C.; Duarte, L. T.; Alves, M. D. L.; Habert, A. C.; Borges, C. P. Recent Achievements in Facilitated Transport Membranes for Separation Processes. Brazilian J. Chem. Eng. 2007, 24 (01), 101-118.

(100) Surya Murali, R.; Yamuna Rani, K.; Sankarshana, T.; Ismail, A. F.; Sridhar, S. Separation of Binary Mixtures of Propylene and Propane by Facilitated Transport through Silver Incorporated Poly(Ether-Block-Amide) Membranes. Oil Gas Sci. Technol. - Rev. d'IFP Energies Nouv. 2015, 70 (2), 381-390.

(101) Wang, Y.; Ren, J.; Deng, M. Ultrathin Solid Polymer Electrolyte PEI/Pebax2533/AgBF4 Composite Membrane for Propylene/Propane Separation. Sep. Purif. Technol. 2011, 77 (1), 46-52.

(102) Kang, S.; Kim, J.; Won, J. Enhancement of Facilitated Olefin Transport by Amino Acid in 
Silver-Polymer Complex Membranes. Chem. Commun. 2003, (6), 768-769.

(103) Kim, J. H.; Park, S. M.; Won, J.; Kang, Y. S. Unusual Separation Property of Propylene/Propane Mixtures through Polymer/Silver Complex Membranes Containing Mixed Salts. J. Memb. Sci. 2005, 248 (1-2), 171-176.

(104) Preechatiwong, W.; Schultz, J. M. Electrical Conductivity of Poly(Ethylene Oxide)-Alkali Metal Salt Systems and Effects of Mixed Salts and Mixed Molecular Weights. Polymer 1996, 37 (23), 5109-5116.

(105) Jose, B.; Ryu, J. H.; Lee, B. G.; Lee, H.; Kang, Y. S.; Kim, H. S. Effect of Phthalates on the Stability and Performance of $\mathrm{AgBF}_{4}$-PVP Membranes for Olefin/Paraffin Separation. Chem. Commun. 2001, 2046-2047.

(106) Hun Park, H.; Won, J.; Oh, S. G.; Kang, Y. S. Effect of Nonionic N-Octyl $\beta$-DGlucopyranoside Surfactant on the Stability Improvement of Silver Polymer Electrolyte Membranes for Olefin/Paraffin Separation. J. Memb. Sci. 2003, 217 (1-2), 285-293.

(107) Pastoriza-Santos, I.; Liz-Marzán, L. M. Formation and Stabilization of Silver Nanoparticles through Reduction by $N, N$-Dimethylformamide. Langmuir 1999, 15 (4), 948-951.

(108) Wistrand, L. Silver Tetrafluoroborate. In e-EROS Encyclopedia of Reagents for Organic Synthesis; John Wiley \& Sons, 2005; pp 1-8.

(109) Kang, S. W.; Kim, J. H.; Won, J.; Kang, Y. S. Suppression of Silver Ion Reduction by Al(NO3)3 Complex and Its Application to Highly Stabilized Olefin Transport Membranes. J. Memb. Sci. 2013, 445 (3), 156-159. 
(110) Park, Y. S.; Kang, Y. S.; Kang, S. W. Cost-Effective Facilitated Olefin Transport Membranes Consisting of Polymer/AgCF $3 \mathrm{SO}_{3} / \mathrm{Al}\left(\mathrm{NO}_{3}\right)_{3}$ with Long-Term Stability. $J$. Memb. Sci. 2015, 495 (3), 61-64.

(111) Kang, S. W.; Hong, J.; Char, K.; Kim, J. H.; Kim, J.; Kang, Y. S. Correlation between Anions of Ionic Liquids and Reduction of Silver Ions in Facilitated Olefin Transport Membranes. Desalination 2008, 233 (1-3), 327-332.

(112) Park, Y. S.; Kang, S. W. Role of Ionic Liquids in Enhancing the Performance of the Polymer/AgCF $\mathrm{SO}_{3} / \mathrm{Al}\left(\mathrm{NO}_{3}\right)_{3}$ Complex for Separation of Propylene/Propane Mixture. Chem. Eng. J. 2016, 306, 973-977.

(113) Arcella, V.; Troglia, C.; Ghielmi, A. Hyflon Ion Membranes for Fuel Cells. Ind. Eng. Chem. Res. 2005, 44 (20), 7646-7651.

(114) Kang, S. W.; Kim, J. H.; Char, K.; Kang, Y. S. Chemical Activation of $\mathrm{AgNO}_{3}$ to Form Olefin Complexes Induced by Strong Coordinative Interactions with Phthalate Oxygens of Poly(Ethylene Phthalate). Ind. Eng. Chem. Res. 2006, 45 (11), 4011-4014.

(115) Song, D.; Kang, Y. S.; Kang, S. W. Highly Permeable and Stabilized Olefin Transport Membranes Based on a Poly(Ethylene Oxide) Matrix and $\mathrm{Al}\left(\mathrm{NO}_{3}\right)_{3}$. J. Memb. Sci. 2015, $474(0), 273-276$.

(116) Chevron Phillips Chemical Company LP http://www.cpchem.com/enus/Pages/default.aspx (accessed Jul 12, 2017).

(117) Huang, Y.; Merkel, T. C.; Baker, R. W. Pressure Ratio and Its Impact on Membrane Gas Separation Processes. J. Memb. Sci. 2014, 463, 33-40. 
(118) Pozun, Z. D.; Tran, K.; Shi, A.; Smith, R. H.; Henkelman, G. Why Silver Nanoparticles Are Effective for Olefin / Paraffin Separations. J. Phys. Chem. C 2011, 115, 1811-1818.

(119) Chae, I. S.; Kang, S. W.; Park, J. Y.; Lee, Y. G.; Lee, J. H.; Won, J.; Kang, Y. S. Surface Energy-Level Tuning of Silver Nanoparticles for Facilitated Olefin Transport. Angew. Chemie - Int. Ed. 2011, 50 (13), 2982-2985.

(120) Choi, H.; Lee, J. H.; Kim, Y. R.; Song, D.; Kang, S. W.; Lee, S. S.; Kang, Y. S. Tetrathiafulvalene as an Electron Acceptor for Positive Charge Induction on the Surface of Silver Nanoparticles for Facilitated Olefin Transport. Chem. Commun. 2014, 50 (24), 3194-3196.

(121) Kang, S. W.; Char, K.; Kang, Y. S. Novel Application of Partially Positively Charged Silver Nanoparticles for Facilitated Transport in Olefin/Paraffin Separation Membranes. Chem. Mater. 2008, 20 (4), 1308-1311.

(122) Chae, I. S.; Kang, S. W.; Kang, Y. S. Olefin Separation via Charge Transfer and Dipole Formation at the Silver Nanoparticle-Tetracyanoquinoid Interface. $R S C A d v$. 2014, 4 (57), 30156-30161.

(123) Lee, J. H.; Kang, S. W.; Yeom, M. S.; Kim, Y. R.; Choi, H.; Song, D.; Won, J.; Kang, Y. S. A Strong Linear Correlation between the Surface Charge Density on Ag Nanoparticles and the Amount of Propylene Adsorbed. J. Mater. Chem. A 2014, 2 (19), 6987.

(124) Shin, H. S.; Yang, H. J.; Kim, S. Bin; Lee, M. S. Mechanism of Growth of Colloidal Silver Nanoparticles Stabilized by Polyvinyl Pyrrolidone in $\gamma$-Irradiated Silver Nitrate Solution. J. Colloid Interface Sci. 2004, 274 (1), 89-94. 
(125) Hong, G. H.; Song, D.; Chae, I. S.; Oh, J. H.; Kang, S. W. Highly Permeable Poly(Ethylene Oxide) with Silver Nanoparticles for Facilitated Olefin Transport. RSC $A d v . \mathbf{2 0 1 4}, 4$ (10), 4905.

(126) Rezende, C. G. F.; Borges, C. P.; Habert, A. C. Sorption of Propylene and Propane in Polyurethane Membranes Containing Silver Nanoparticles. J. Appl. Polym. Sci. 2016, 133 (4), 6-11.

(127) Görner, H. Photoprocesses of p -Benzoquinones in Aqueous Solution. J. Phys. Chem. A 2003, 107 (51), 11587-11595.

(128) Szatylowicz, H.; Krygowski, T. M.; Solà, M.; Palusiak, M.; Dominikowska, J.; Stasyuk, O. A.; Poater, J. Why 1,2-Quinone Derivatives Are More Stable than Their 2,3Analogues? Theor. Chem. Acc. 2015, 134, 35.

(129) Kang, S. W.; Char, K.; Kim, J. H.; Kang, Y. S. Ionic Liquid as a Solvent and the LongTerm Separation Performance in a Polymer/Silver Salt Complex Membrane. Macromol. Res. 2007, 15 (2), 167-172.

(130) Shalu; Chaurasia, S. K.; Singh, R. K.; Chandra, S. Thermal Stability, Complexing Behavior, and Ionic Transport of Polymeric Gel Membranes Based on Polymer PVdFHFP and Ionic Liquid, [BMIM][BF 4 . J. Phys. Chem. B 2013, 117 (3), 897-906.

(131) Zarca, R.; Ortiz, A.; Gorri, D.; Ortiz, I. Generalized Predictive Modeling for Facilitated Transport Membranes Accounting for Fixed and Mobile Carriers. J. Memb. Sci. 2017, $542,168-176$.

(132) Zarca, G.; Horne, W. J.; Ortiz, I.; Urtiaga, A.; Bara, J. E. Synthesis and Gas Separation 
Properties of Poly(Ionic Liquid)-Ionic Liquid Composite Membranes Containing a Copper Salt. J. Memb. Sci. 2016, 515, 109-114.

(133) Zarca, R.; Ortiz, A.; Gorri, D.; Ortiz, I. Facilitated Transport of Propylene Through Composite Polymer-Ionic Liquid Membranes. Mass Transfer Analysis. Chem. Prod. Process Model. 2016, 11 (1), 77-81.

(134) Zarca, R.; Ortiz, A.; Gorri, D.; Ortiz, I. A Practical Approach to Fixed-Site-Carrier Facilitated Transport Modeling for the Separation of Propylene/Propane Mixtures through Silver-Containing Polymeric Membranes. Sep. Purif. Technol. 2017, 180, 82-89.

(135) Fallanza, M.; Ortiz, A.; Gorri, D.; Ortiz, I. Propylene and Propane Solubility in Imidazolium, Pyridinium, and Tetralkylammonium Based Ionic Liquids Containing a Silver Salt. J. Chem. Eng. Data 2013, 58 (8), 2147-2153.

(136) Ortiz, A.; Galán, L.; Gorri, D.; de Haan, A. B.; Ortiz, I. Reactive Ionic Liquid Media for the Separation of Propylene / Propane Gaseous Mixtures. Ind. Eng. Chem. Res. 2010, 49 (16), 7227-7233.

(137) Guo, C. G.; Wang, Q. G.; Zhou, G. D.; Mak, T. C. W. Synthesis and Characterization of $\mathrm{Ag}_{2} \mathrm{C}_{2} \cdot 2 \mathrm{AgClO}_{4} \cdot 2 \mathrm{H} 2 \mathrm{O}$ : A Novel Layer-Type Structure with the Acetylide Dianion Functioning in a M6- H1, H1 : H2, H2: H2, H2 Bonding Mode inside an Octahedral Silver Cage. Chem. Commun. 1998, No. 3, 339-340.

(138) Hamza, A. A.; Martin, J.; Barbouti, M.; Rosales, C.; Perez, J. C.; Towe, I. G. Continuous Olefin/Paraffin Separation with Permylene ${ }^{T M}$ Facilitated Transport Membranes from IMTEX Membranes Corporation; White Paper, 2015. 
(139) Herrera, P. S.; Feng, X.; Payzant, D.; Kim, J. H. Processe for the Separtaion of Olefins from Paraffins Using Membranes. U.S. Patent US7361800 B2, April 22, 2008.

(140) Feng, X.; Towe, I. G.; Hamza, A.; Perez, J. C. Replenishing Liquid Material to Membrane. U.S. Patent 2014/0245884 A1, September 4, 2014.

(141) Compact Membrane Systems (CMS). CMS Optiperm Membrane: A Breakthrough Innovation for the Separation of Olefins and Paraffins; White paper, 2016.

(142) Delaware Company Is Overall Winner of Petrochemical Innovation Awards. The Global Delaware Blog. Wilmington March 11, 2016.

(143) Kattula, M.; Ponnuru, K.; Zhu, L.; Jia, W.; Lin, H.; Furlani, E. P. Designing Ultrathin Film Composite Membranes: The Impact of a Gutter Layer. Sci. Rep. 2015, 5, 1-9.

(144) Galizia, M.; Chi, W. S.; Smith, Z. P.; Merkel, T. C.; Baker, R. W.; Freeman, B. D. 50th Anniversary Perspective: Polymers and Mixed Matrix Membranes for Gas and Vapor Separation: A Review and Prospective Opportunities. Macromolecules 2017, 50 (20), 7809-7843.

(145) Eriksen, O. I.; Aksnes, E.; Dahl, I. M.; Lee, F. M. Use of Silver-Exchanged Ionomer Membranes for Gas Separation. U.S. Patent 5,191,151 A, March 2, 1993.

(146) Feiring, A. E.; Lazzeri, J.; Majumdar, S. Membrane Separation of Olefin and Paraffin Mixtures. U.S. Patent 2015/0025293 A1, January 22, 2015. 


\section{For Table of Contents Only}

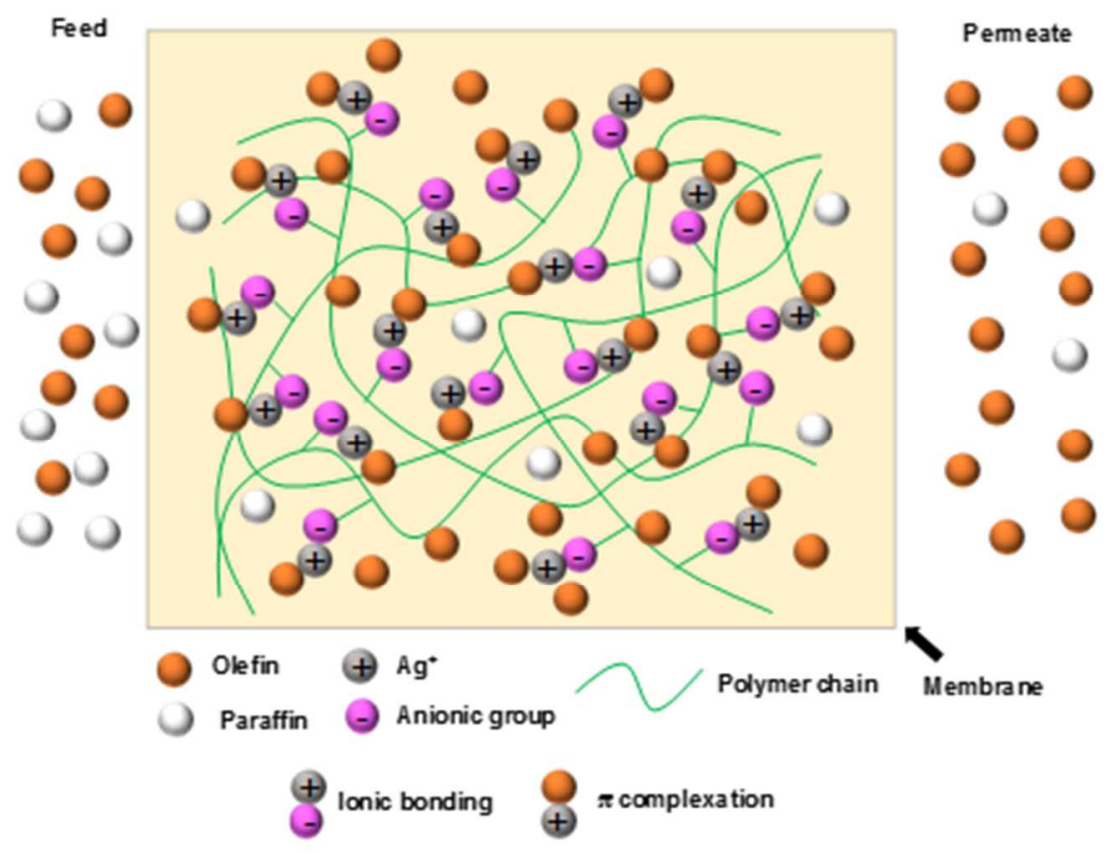

ACS Paragon Plus Environment 


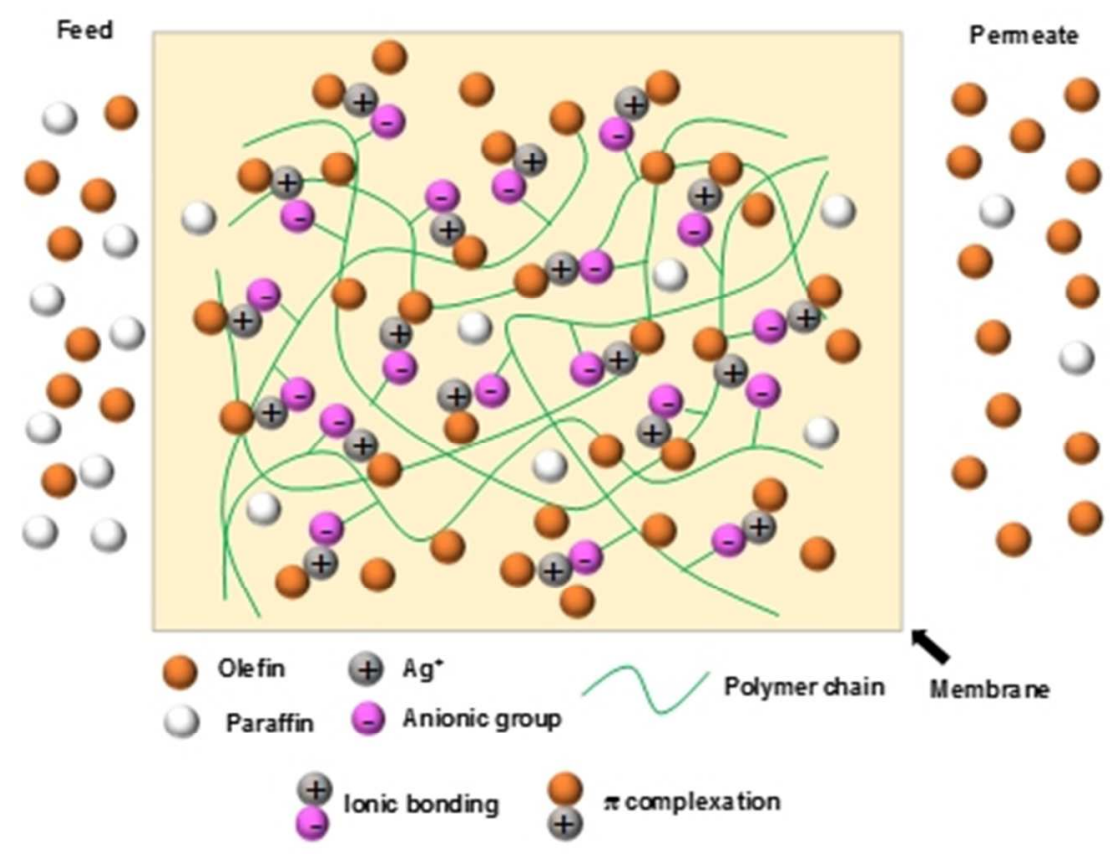

For Table of Contents Only 